\title{
Normative Evaluation of Tax Policies: from Households to Individuals*
}

\author{
Olivier Bargain ${ }^{\dagger}$
}

November 2004

\begin{abstract}
In this paper, we analyze the impact of a tax policy change on social welfare by using jointly a collective model of household labor supply and a microsimulation program of the French tax-benefit system. The collective approach allows studying the intrahousehold distribution so that for the first time, social welfare can be characterized using individual utilities rather than an ambiguous concept of household welfare. This way, the planner's preferences address not only inter-household inequalities but also intra-household inequalities often neglected in the literature. The other contribution of the paper derives from a larger interpretation of labor supply behaviors which represent more than the simple work duration and incorporate unobserved dimensions related to effort or intensity at work. We simulate an extended version of the British Working Family Tax Credit on married couples in France. Two types of conclusions emerge. First, the reform is not desirable for low values (utilitarian) or high values (rawlsian) of the social inequality aversion but rather for an intermediary range. In effect, on the efficiency side, the reform induces strong disincentive effects on the participation of second-earners while on the equity side, it does not specifically target the poorest households. Second, we show that the choice of unit - household or individual - strongly condition the results of the normative analysis when departing in a reasonable way from the assumption of equal sharing within the household.
\end{abstract}

Key Words : collective model, intrahousehold distribution, social welfare, household labor supply, microsimulation, tax reform.

Classification JEL : C71, D13, D31, D63, H21, H31, J22.

\footnotetext{
*Acknowledgements : I am grateful to François Bourguignon, Olivier Donni, Guy Lacroix, and Catherine Sofer for useful comments and suggestions. I would especially like to thank François Laisney and Nicolas Moreau for in-depth review of the first draft and to Amedeo Spadaro for numerous methodological advices. All errors or omissions remain mine.

${ }^{\dagger}$ IZA, Bonn, and DELTA, Paris. Correspondence: P.O. Box 7240, D-53072 Bonn, Germany. Email: bargain@iza.org.
} 


\section{Introduction}

Inequality across individuals in a population can be seen as a function of inter-household inequality and total intra-household inequality, the latter being most often neglected in the literature. Using observations on individual levels of consumption, Haddad and Kanbur (1990) show that poverty and inequality measures are strongly biased by this approximation. More generally, it is meaningful to question the nature of this bias when looking at the distribution of welfare among individuals and the impact of social and fiscal rules on this distribution. It seems indeed natural to think that the ultimate object of concern of tax and benefit policies is the welfare of individuals. Yet, the household represents a black box from which it is difficult to infer information relative to the welfare of its members. The public decider is usually constrained to assume that an equal sharing takes place within families.

The present paper addresses precisely these issues and suggests a normative framework to analyze tax policy in which social preferences are concerned by individual utilities instead of the ambiguous concept of 'household welfare'. Individual level data are rare and even more difficult is the measure of individual welfare so that we resort to the use of a structural multi-utility model with minimalist assumptions regarding preferences. Moreover, social evaluation of welfare - at individual or household level - requires the formal framework of the optimal taxation theory. This way, the paper suggests one of the very first attempts to reconcile two branches of the economic literature which are usually dissociated.

On the one hand, we benefit from the collective model of labor supply (cf. Chiappori, 1988, 1992) which acknowledges explicitly the presence in the household of several deciders whose preferences may differ. The decision making process - the incentive constraint of the social planner - relies on the sole assumption that household decisions are Pareto-efficient. This setting allows studying the intra-household distribution of resources and welfare.

On the other hand, the normative evaluation of tax-benefit policies is possible thanks to an explicit modeling of the equity-efficiency trade-off faced by the planner. In the model of Mirrlees (1971), the level of productivity is unobservable and instead of taxing talents, the planner must target labor income, which is observed but depends on productive behaviors (second-best). Even though the model has raised great interest in the 1970s, only general results have been derived regarding the properties of an optimal tax system. More precise characterizations are not possible unless one is ready to make very crude assumptions on the various 'ingredients', when implementing the model, or on the structure of the tax system (flat marginal tax rates). ${ }^{1}$

In the recent years, the use of microdata combined with tax-benefit microsimulation programs has contributed to the revival of this literature and has raised new questions (see Bourguignon and Spadaro, 2002). The implementation of the optimal tax model requires among other things the knowledge of social preferences and individual preferences. The issue of social preferences can be seen as a subject of research per se. In principle, it is possible to derive the optimal tax schedule for different values of the social aversion to inequality and identify the level for which the optimal schedule coincides with the actual one. ${ }^{2}$

\footnotetext{
${ }^{1}$ See Atkinson and Stiglitz (1980) or Tuomala (1990) for a general presentation.

${ }^{2}$ This way, Laroque (2002) shows that an optimal tax schedule derived from rawlsian preferences is relatively close to the actual schedule in France. Spadaro (2004) also shows that the French tax system dominates the British one - when simulated on French data - except for the assumption of high elasticities and for a low level of social inequality aversion. Since the actual system in France is likely to be closer to the optimum based on social preferences than an alternative system as the British one, it is possible to conclude that the French system is not utilitarist (or less so than the British one) or implicitly assumes low elasticities in the population. In a somewhat symmetrical way, Bourguignon and Spadaro (2000b) assume that the actual system reflects social preferences - hence fully coincide with the optimal schedule - so that
} 
As for individual consumption-leisure preferences, our knowledge is still limited. The relative consensus which has emerged from the bursting literature of the last twenty years is not precise. Most importantly, it establishes that income-elasticity is negative and that the own wage-elasticity stands in $[0,1]$, is larger for married women and is mostly driven by changes at the extensive margin (cf. Blundell and MaCurdy, 1999, Heckman, 1993). When it comes to define more precisely the value of elasticities, a large number of unknowns remains. This issue is critical insofar as the size of wage-elasticities, either closer to zero or closer to unity, conditions the conclusions of the equity-efficiency trade-off in a crucial way. Two approaches have been adopted in recent applications of the optimal tax theory. On one side, some authors trust the econometric approach and rely on the latest techniques to estimate country-specific elasticities as accurately as possible. This is the choice of Laroque (2002) for France, using the empirical work of Laroque and Salanié (2002). This is also the approach retained by Hagneré et al. (2002) to analyze the optimal design of an earned income tax credit in France. On the other side, one might acknowledge the numerous limitations to labor supply estimations and decide to analyze the results of the Mirrlees model in the light of several arbitrary levels of labor supply responsiveness, as suggested by Spadaro (2004) and Bourguignon and Spadaro (2000a, 2000b). This is actually the choice made in the present exercise.

Despite recent developments among the studies quoted above, the Mirrlees model remains a onedimension framework where productivity is the unique source of heterogeneity across agents while labor supply is the only choice variable. ${ }^{3}$ Several concerns arise out of this.

Consider primarily a population of childless couples. Firstly, the extension of the model to twoproductivity households would already make it unsolvable. ${ }^{4}$ A solution, retained by Spadaro (2004) and Bourguignon and Spadaro (2000a, 2000b), consists of treating households of more than one person as an entity from which one can derive an aggregated total labor supply and a household productivity (some kind of interpolation of household members' productivities). Secondly, the model cannot account for several decision makers in the household unless one assumes that the negotiation rule is uniform in the population, i.e. it does not imply further heterogeneity across households, ${ }^{5}$ or is optimal for the policy maker. ${ }^{6}$ Thirdly, the issue surrounding the unit of analysis extends to the taxation itself. In particular, the model allows to derive optimal marginal tax rates only at the household level and tells nothing about the optimal taxation of individuals. Yet, tax schedules in many countries are based on individuals (while actual redistributive systems are rather targeted to households). Even in systems with joint taxation, as in France, recent debates exhibit a progressive evolution toward an individual perspective at odds with the traditional family-oriented philosophy. ${ }^{7}$

In addition, the model necessarily considers identical households with respect to household composition while demographic heterogeneity implies different needs across families. In other words, social preferences in the Mirrlees framework are concerned only with vertical equity while actual tax-benefit

\footnotetext{
these preferences can be retrieved by inversion of the optimal taxation model.

${ }^{3}$ About multidimensionality in optimal taxation theory, see Mirrlees (1986).

${ }^{4}$ Boskin and Sheshinski (1983) do so but get rid of the multidimensionality by assuming some fixed correlation between spouses' productivities.

${ }^{5}$ In that case, the negotiation rule does not depend on household characteristics (such as wage rates) and the model, as in Samuelson (1956), is not empirically different from a unitary model. Peluso and Trannoy (2003) resort to this type of model to derive regularity conditions - essentially the concavity of the sharing rule - under which conclusions regarding the inequality across households also apply to the inequality across individuals.

${ }^{6}$ This assumption of 'non-dissonance' between social preferences and 'household preferences' is made by Apps and Rees (1999) who study only efficiency aspects and ignore intra-household distribution and individual welfare.

${ }^{7}$ The individualization of the income tax scheme - and more generally the individualization of rights - is actively discussed in France and has been applied in Belgium some years ago.
} 
systems incorporate implicit judgment regarding horizontal equity. In general, this aspect is rarely accounted for in the literature. ${ }^{8}$ In particular, the recent applications of the optimal taxation theory restrict the analysis to a sub-population of homogenous households, most often childless single individuals (for instance, see Choné and Laroque, 2001, Hagneré et al., 2002). ${ }^{9}$

The present paper addresses some of these issues and mostly suggests a consistent framework to extend the evaluation of social welfare to individuals. This way, the exercise focuses voluntarily on couples (with or without children). ${ }^{10}$ The hypothesis of interpersonal comparability becomes less stringent here insofar as we compare the utility levels of individuals rather than those of households with different composition. In addition, the incentive compatibility constraint of the planner accounts for the fact that some individuals live and interact within a given household. We maintain the assumption of homogenous preferences across individuals but allow households to differ as the bargaining rule depends on householdspecific characteristics.

Following Spadaro (2004), we do not attempt to derive the optimal tax schedule but simply to conclude if a reform improves social welfare or not, that is, if it brings the system in force closer to the optimal frontier. This discrete analysis allows using survey data in order to account for several sources of heterogeneity across households (capital income, productivity of both spouses, household size and composition, etc.). Among other things, this heterogeneity influences the computation of taxes and benefits in the real world and all the complexity of the tax-benefit system is incorporated using a microsimulation program. Then, the analysis goes beyond the one-dimension set-up of the Mirrlees model.

Also, the productivity of agents is assumed to be unobservable insofar as it does not coincide with their wage rate (calculated as earnings divided by working time). In effect, several authors have emphasized the fact that work duration is only one aspect of the labor supply decision. The overall productive effort which generates observed income may well be related to other unobservable dimensions such as intensity of work, mobility, learning effort, etc. This limitation to the traditional model of labor supply is often recalled, in particular in the optimal taxation framework where it serves to justify that productivities are unobservable. Yet, this dimension is rarely exploited in empirical works on taxation and receives special attention here.

The necessary reinterpretation of the labor supply model implies a somewhat symmetrical approach to the econometric one as preferences are assumed to be known while exogenous productivity of each spouse must be retrieved by inversion of the household program at its optimum. To simulate household behaviors, we posit a very simple bargaining rule whose only virtue is to allow a reasonable depart from the equal sharing assumption. Two regimes of individual preference are chosen in order to obtain low and high levels of responsiveness of productive efforts, giving the upper and lower bounds in line with the literature for married men and women separately. We explore the sensitivity of the results to these various levels of elasticities.

The layout of the paper is as follows. In Section 2, we describe the program of the social planner and the program of the household together with the specification choices. In Section 3, we present the approach

\footnotetext{
${ }^{8}$ The study of Muellbauer and Van de Ven (2004) is among the most interesting exceptions as they compare traditional equivalence scales with the equivalence scales implicit in the tax-benefit system in Australia and their relation to horizontal equity.

${ }^{9}$ It is possible to apply Mirrlees model separately to different uniform sub-groups. However, this approach assumes that redistribution across groups occurs exogenously in a second stage while tax systems in force account simultaneously for both vertical and horizontal redistribution.

${ }^{10}$ Note that in our study, we assume that children do not have any bargaining power so that their preferences are internalized in those of the parents. Family dimension is accounted for by use of an equivalence scale based on some judgments implicit in the French tax-benefit system.
} 
to retrieve individual productivities and analyze the results by comparing calibrated productivities and wage rates as well as work hours and productive efforts. In particular, we investigate the error committed in the studies which ignore potential inequality within the household. In Section 4, we describe the tax reform and show how the normative analysis changes when the planner has the possibility to infer household distribution rules. Section 5 concludes.

\section{Social and Individual Welfare}

\subsection{The Planner's Program}

\subsubsection{Social Welfare Evaluation}

Using jointly a tax-benefit microsimulation program and a modeling of productive behaviors, we seek to analyze the effects of fiscal and redistributive policies on social welfare. In this respect, our framework is inspired by the optimal taxation model $\grave{a}$ la Mirrlees in which the social planner chooses the tax schedule, symbolized by function $g$, which maximizes social welfare under a budget constraint and an incentivecompatibility constraint. The latter corresponds to household optimal productive behaviors for a given tax-benefit system.

To solve the model would be too complicated in the following set-up as we intend to account for numerous sources of heterogeneity across households. We then restrict the problem to the evaluation of social welfare for two specific tax-benefit systems, the situations before and after a reform. The tax reform approach is simply a discrete version of the optimal taxation framework which investigates whether the post-reform situation gets closer or not to the equity-efficiency frontier. This approach may appear more realistic as it implies gradual reforms of the actual system instead of a complete change following an optimal tax schedule. In addition, as recalled in the introduction, the optimal taxation model provides only results on effective marginal tax rates and is not informative on equivalence scales or specific taxation of household members. In contrast, here, it is possible to choose $g$ so that it incorporates the whole tax-benefit system and in particular the rules relative to the treatment of family dimension.

Denoting $V_{i_{h}}$ the level of utility reached by individual $i$ in household $h$, we evaluate social welfare $S W$ as follows:

$$
S W=\sum_{h} \sum_{i_{h}} \Psi\left[V_{i_{h}}\left(\omega_{h}, g, \zeta_{h}\right)\right]
$$

where $\Psi$ is a social welfare function, usually assumed to be non-decreasing and concave with respect to utility levels. The determinants of individual indirect utilities are a vector $\omega_{h}$ of members' productivities in household $h$, a vector $\zeta_{h}$ of characteristics concerning the household and its environment, and the tax-benefit system $g$.

Originally, the evaluation of social welfare in expression (1) is concerned with individual utilities rather than an index of 'household welfare'. Individual welfare for individuals in couples is obtained by an application of the collective model of labor supply with private consumption (see Chiappori, 1988, 1992). ${ }^{11}$ To clarify the intuitions and interpretation of the results in the following, we only focus on couples while it is must be stressed that the suggested set-up can easily extend to all individuals in the population to eventually conduct a comprehensive tax policy analysis. ${ }^{12}$

\footnotetext{
${ }^{11}$ Recent introduction of public goods in collective models of consumption can be found in Chiappori, Blundell, and Meghir (2002), Lewbel et al. (2002), and Donni (2004a).

${ }^{12}$ In this case, however, it would be necessary to correct couples' consumption to account for economies of scales compared
} 


\subsubsection{The Planner's Constraints and Specification of Social Preferences}

We assume that children's preferences are internalized into those of their parents, an hypothesis usually retained in the collective model literature. ${ }^{13}$ Household $h$ is then essentially seen as two spouses, the wife $f$ and the husband $m$, with their own consumption $c_{i_{h}}\left(i_{h}=f_{h}, m_{h}\right)$, their level of productive effort $e_{i_{h}}$ and their own preferences gathered in a well-behaved direct utility function $U_{i_{h}}$.

As in Chiappori $(1988,1992)$, we assume only the efficiency of household decisions. This way, the household optimal program which represents the incentive constraint of the planner can be written very generally as follows, for $i_{h}, j_{h}=f_{h}, m_{h}$ :

$$
\begin{aligned}
V_{i_{h}}\left(\omega_{h}, g, \zeta_{h}\right) & =\max _{c_{h}, c_{j_{h}}, e_{h}, e_{j_{h}}}\left[U_{i_{h}}\left(c_{i_{h}}, c_{j_{h}}, e_{i_{h}}, e_{j_{h}}\right)\right. \\
\text { s.t. } U_{j_{h}}\left(c_{i_{h}}, c_{j_{h}}, e_{i_{h}}, e_{j_{h}}\right) & \geq u_{j_{h}}\left(\theta_{h}\right) \\
\text { s.t. } c_{f_{h}}+c_{m_{h}} & \left.=g\left(\omega_{f_{h}} e_{f_{h}}, \omega_{m_{h}} e_{m_{h}}, Z_{h}\right)\right] .
\end{aligned}
$$

The negotiated level of utility $u_{j_{h}}\left(\theta_{h}\right)$ depends on a vector $\theta_{h}$ of household characteristics (spouses' productivities, level of non-labor income) and environmental factors which could influence intra-household bargaining. Individual preferences depend in this general expression on both the person's and her partner's demands, allowing all sorts of externalities. Most of the studies aimed at testing the collective rationality assume, however, a separability property between each spouse's choice variables and most of the time, simply resort to egoistic preferences. ${ }^{14}$ Our specification stands half-way, as shall be seen below. The household budget constraint makes explicit how the total level of consumption $c_{f_{h}}+c_{m_{h}}$, which corresponds to household disposable income in a static setting, results from individual gross income revenues $y_{i_{h}}=\omega_{i_{h}} e_{i_{h}}$ (for $i_{h}=f_{h}, m_{h}$ ), household characteristics $Z_{h}$, including demographic characteristics and the level of non-labor income, and the function $g .{ }^{15}$

The planner must also respect the public budget balance. Denoting $B$ the tax revenue objective and ignoring non-labor income for a moment, this budget constraint is written: ${ }^{16}$

$$
B=\sum_{h} \sum_{i_{h}}\left(\omega_{i_{h}} e_{i_{h}}-c_{i_{h}}\right)
$$

Tax revenues $B$ are certainly not null in the real world but their use does not need to be specified here. The important aspect in the tax reform approach is that the cost of the reform must be offset somehow in order to assure budget neutrality, i.e. keep the constraint binding. In this respect, we assume the introduction of a tax/subsidy on consumption simultaneous to the reform. This point is detailed in the sequel.

In a very usually way with respect to the literature on optimal taxation, we specify the social welfare function as follows:

$$
\Psi(V)=\frac{V^{1-\gamma}}{1-\gamma}
$$

to single life. Another route consists in modeling explicitly household technology's returns of scale in the way suggested by Lewbel et al. (2002).

${ }^{13}$ Bourguignon (1999) is an exception. See also the recent extension of the collective model from Dauphin and Fortin (2000) and Dauphin et al. (2002).

${ }^{14}$ Browning and Chiappori (1998) is a notable exception.

${ }^{15}$ Vector $\zeta_{h}$ in (1) is simply the union of $\theta_{h}$ and $Z_{h}$.

${ }^{16}$ Naturally, our restriction to the case of couples and the imposition of a budget constraint on this sub-population is artificial and corresponds only to the needs of our exercises. Future applications of this methodology should apply both the reform and the planner's budget constraint on the whole population. 
This function is a concave transformation of cardinal individual utilities into social welfare and the degree of concavity - represented by $\gamma$ - translates the social aversion to inequality. We eventually analyze the sensitivity of the results to different levels of this parameter between 0 (utilitarian preferences) et $+\infty$ (rawlsian preferences).

\subsection{Households' Program}

\subsubsection{Reinterpretation of the Labor Supply Model}

Following Spadaro (2004) and Bourguignon and Spadaro (2000a et 2000b), we assume that working hours do not reflect 'true' labor supply behaviors. In effect, the productive efforts which generate observed earnings probably exceed the work duration and incorporate unobservable dimensions such as intensity of work, learning effort, mobility, etc. This various aspects are studied in other branches of the economic literature but surprisingly, are rarely accounted for in the vast empirical literature on labor supply and taxation. This point is nonetheless important insofar as the effects of a tax reform are likely to exceed the simple variations of working time usually captured in the estimations. The best example for this is the major US reform of 1986, which mainly consisted in a sharp reduction of marginal tax rates. Initiating the new tax responsiveness literature, Feldstein (1995) shows that taxable incomes have responded more intensively than work duration to the reform.

The argument is widely spread in the optimal taxation literature as it justifies the fact that agents' productivities cannot be observed by the government, even though labor income $y$ and weekly working time $h$ are observable so that hourly wage can be computed as $w=y / h \cdot{ }^{17}$ In effect, the latter does not reflect the exogenous productivity of an agent insofar as the true productive effort $e=h+\varepsilon$ is not limited to work duration $h$ but also includes an individual disturbance $\varepsilon$ that can be seen as choices of work intensity or effort at work and treated more generally as a measurement error. True productivity, written $\omega=y /(h+\varepsilon)$, is an unobservable exogenous parameter that must be retrieved.

\subsubsection{A Symmetrical Approach}

To calibrate individual productivities, we then suggest an approach somewhat symmetrical to the usual econometric method. Using observed earnings $y^{*}$ and assuming that they correspond to optimal choices $y=w h(w)$, the 'natural' approach consists of estimating homogenous preferences encapsulated in the close form $h()$ and rely on the assumption that productivities are observable. ${ }^{18}$ Using the same earnings $y^{*}$ and assuming that they coincide with optimal choices $y=\omega e(\omega)$, we suggest retrieving productivities $\omega$ under some simple assumptions on preferences in $e()$. The strategy simply consists in the inversion of the household optimal program in order to calibrate individual productivities from the observation of earnings $y$. It has been suggested by Spadaro (2004) and Bourguignon and Spadaro (2000a and 2000b) in the unitary case and is extended here to the collective model.

Our approach does not require estimating the elasticities of effort supply. Instead, the social welfare evaluation is conducted for several orders of magnitude of these elasticities. A justification to this choice,

\footnotetext{
${ }^{17}$ The implementation of the second best then relies on labor income, endogenous to productive behaviors. In the real world too, taxation usually targets earnings but there are exceptions. For instance, the newly implemented tax credit on earned income (Prime Pour l'Emploi) requires the knowledge of the working time over the year in order to compute a full-time equivalent income which is nothing else than a linear transformation of the hourly wage rate. The idea behind this is indeed to target full-time low-productive workers instead of talented part-time workers.

${ }^{18} \mathrm{Or}$, in other words, that wage rates $w=y / h$ can be taken as a proxy for productivity insofar as observed hours $h$ represent the comprehensive supply of productive effort.
} 
mentioned in the introduction, is related to the lack of robustness in the estimation of structural models of labor supply together with the lack of precision for the values of wage-elasticities. ${ }^{19}$ Naturally, the limitation of the continuous approach of Hausman (1981), and in particular the critics from MaCurdy (1992), are now overcome thanks to the recent development of discrete choice models as the one used in Blundell et al. (2000). With the increasing number of national evaluations, one may hope to obtain new series of more precise elasticities. Yet, few studies account for all the recurrent limitations in labor supply estimation and in particular (i) the fact that observed hours are usually rationed (while desired hours are rarely available), (ii) the fact that wage rates are assumed not to vary with working time, (iii) the assumption of static and unitary households in a partial equilibrium.

The point (i) above make our approach especially interesting for countries like France where individuals are constrained in their working time. In effect in the traditional econometric approach, preferences are estimated relying on the observed hours while a large number of individuals are compelled to work at the legal full-time duration (39 hours per week 1998, the year of interest). Distribution of working hours are indeed very concentrated as shown for instance by Bargain and Orsini (2004). Estimates are then likely to capture more than pure preferences and in particular, may be 'contaminated' by institutional and demand-side rigidities. Yet, even if declared hours are very concentrated, one may well think that the large spread in earnings translates a large diversity of productive behaviors which express themselves through other channels than work duration.

Finally, the approach is all the more appropriate that there is no easy econometric strategies to estimate a collective model yet, especially in a set-up with nonlinear taxation and simultaneous choices of hours and participation. ${ }^{20}$ Also, the rare attempts to operationalize a cooperative model of labor supply have relied on simulation and have made use of observed hours so that the same critics as above applies (see for instance Bargain and Moreau, 2002).

\subsubsection{Specification of the Collective Model of Productive Effort}

An easy way to model collective rationality is to replace the general representation of Pareto efficiency in (2) by the maximization of a convex combination of individual utilities which is written as follows (subscript $h$ is taken out to lighten notations):

$$
W=\mu U_{f}\left(c_{f}, e_{f}, e_{m}\right)+(1-\mu) U_{m}\left(c_{m}, e_{m}, e_{f}\right) .
$$

There is a straight equivalence between the general formulation in (2) and the maximization of the linear function of the spouses' utilities as long as the utility possibility set is convex (cf. Chiappori, 1992). In turn, convexity is guaranteed if individual utilities are strictly concave and the budget set is strictly convex. The first condition is easily respected with mild restrictions on the functional form while the second requires more caution. The French tax-benefit system may indeed generate non-convex budget sets, in particular for low-productivity households potentially recipients of means-tested social transfers. In effect, for those, the first hours worked are rewarded by small earnings which are automatically offset by a corresponding decrease of the level of social assistance. This is the well-known poverty trap effect. In what follows, we shall describe how stochastic corrections to the model allow taking these household out

\footnotetext{
${ }^{19}$ For instance in France, recent estimations relying on discrete choice models and a multinomial logit give wage-elasticities around 0.5 (see Bargain and Orsini, 2004) while previous studies using the Hausman technique, and in particular Bourguignon and Magnac (1990), found much higher elasticities (around 1).

${ }^{20}$ See Blundell et al. (2001) for an estimation with participation decisions and Moreau and Donni (2002) for an estimation with nonlinear taxation.
} 
of the non-convex part of their budget set in order to make the model perfectly consistent with optimizing behavior in a static environment. This way, we are assured that the efficient allocation chosen by a given household can be supported as the maximum of the linear form (3).

In this objective function, weight $\mu$ on the wife's utility is an index for her bargaining power in the household. This index depends on a certain number of exogenous parameters likely to influence the intra-household negotiation process and previously represented by vector $\theta_{h}$. Wage rates and non-earned income are obvious candidates despite the fact that their exogeneity can be seriously questioned. Other factors - distribution factors or environmental factors - may affect the negotiation in favor of one spouse or the other (see Bourguignon et al., 1995, and McElroy, 1990). As mentioned by Browning and Lechene (2001) however, the theory around collective models does not give any guidance as to what variables should appear in the set of distribution factors. This difficulty is inherent in the collective approach insofar as Pareto weights on individual utilities are only a reduced form of the negotiation. Consequently, here, we opt for a very simple bargaining rule which depends solely on spouses' abilities:

$$
\mu=\frac{\omega_{f}}{\omega_{f}+\omega_{m}},
$$

these productivities being truly exogenous by definition. The only merit of this rule is to depart somehow from the hypothesis of equal sharing within the household, postulating the role of the spouses' relative potential earnings in the decision making process. ${ }^{21}$ Note that contrary to Bargain and Moreau (2002), taxation does not enter the ratio (4) of gross productivities. ${ }^{22}$ Note also that this is the ratio of potential earnings of the spouses. This conveys two remarks. Firstly, if the ratio of earnings was chosen in this model of labor supply, the bargaining rule would be endogenous to productive behaviors of household members and the efficiency hypothesis would fall in this case, as in Basu (2001). Secondly, this close form of the negotiation process captures the essence of more structural cooperative models and in particular the fact that individual 'outside options' depend positively and above all on the productivity. If one has the early models of Manser and Brown (1980) and McElroy and Horney (1981) in mind, in which the reference situation is divorce, it is rather intuitive to think that ceteris paribus, a more productive individual - probably more educated as well - has better chances to succeed on the 'remarriage market' and on the labor market, generating larger incomes and benefiting overall from a larger reservation utility.

\subsubsection{Specification of Individual Preferences}

We assume individual preferences of the Stone-Geary type with an extra additive term accounting for the partner's disutility of work:

$$
U_{i}\left(c_{i}, e_{i}, e_{j}\right)=\beta_{i}^{c} \ln \left(c_{i}-\underline{c}_{i}\left(Z_{h}\right)\right)+\beta_{i}^{l} \ln \left(T_{i}-e_{i}\right)+\delta \ln \left(T_{j}-e_{j}\right) \quad \text { pour } i, j=f, m .
$$

This functional form is also used by Kooreman and Kapteyn (1990) and Barmby (1994), who assumed public consumption. ${ }^{23}$ In a LES, $T_{i}(i=f, m)$ is usually taken as the total time endowment minus a minimum requirement accounting for physiological regeneration and standardized aspects of household

\footnotetext{
${ }^{21}$ See Beninger and Laisney (2002) for similar choices. Also, in Browning et al. (1994) and Lise and Seitz (2004), the sharing rule depends essentially on the ratio of spouses' earnings and their age difference.

${ }^{22}$ Yet, tax-benefit policies are often suspected to influence the negotiation rule. See Bargain and Moreau (2002) for a discussion.

${ }^{23}$ Kooreman and Kapteyn use information on desired working hours to capture individual consumption-leisure preferences while actual observed hours complete the identification of the bargaining rule, assumimg that desired and observed hours differ only because of different preferences between husband and wife. It is possible, however, that other constraints than marital life prevent individuals to choose a working time according to their wishes - in particular demand-side constraints.
} 
production so that $T_{i}$ reflects the maximum time weekly available for market activity. Here, we interpret $T_{i}$ more broadly as the maximum productive effort which can be accomplished by the worker over a week. Also, the 'effective leisure' is written for $i=f, m$ :

$$
\begin{aligned}
T_{i}-e_{i} & =T_{i}-\left(h_{i}+\varepsilon_{i}\right) \\
& =l_{i}-\varepsilon_{i}
\end{aligned}
$$

that is, the usual concept of leisure $l_{i}$ minus the effort component. If positive, the latter may be thought of as some additional tiredness which prevents from (i) enjoying fully the $l_{i}$ weekly hours of leisure so that 'effective leisure' is smaller, (ii) producing the whole of domestic goods usually produced from the time input $l_{i}$. The second point is naturally an extrapolation since the model does not explicitly account for domestic production. Following the bulk of the literature, we interpret non-market time as leisure. ${ }^{24} \mathrm{We}$ also assume that on average, the model coincides with the usual interpretation in term of labor supply, that is, that mean effort corresponds to the average working time (for men and women separately) or, in other words, that the unobservable term $\varepsilon$ is distributed with a zero mean. ${ }^{25}$

We also treat children as an additional source of private consumption for each spouse. In this respect, the minimum amount of individual consumption $\underline{c}_{i}\left(Z_{h}\right)$ is assumed to be half of the household's minimum consumption, defined for each type of household composition as the lowest disposable income in the related group. Consequently, these amounts depend on public transfers and vary in function of the number of children according to the implicit equivalence scales of minimum income schemes and household benefits. These calibrated terms are in line with the usual specification of the LES utility and can be seen as an additive equivalence scale. On this issue, Muellbauer and Van de Ven (2004) recalled the difficulties specific to comparisons of welfare across households of different composition and the fact that equivalence scales estimated from expenditure data necessarily depend upon exogenously imposed value judgments. Interestingly for our study, they emphasize that the intuitive appeal of equivalence scales based on a country's transfer system is the perception that these relativities embody a social consensus.

\section{Empirical Application}

\subsection{Selected Data}

The data used are selected from the French Household Budget Survey 1994 (INSEE) and monetary variables have been grossed up to 1998, our year of reference, assuming the demography constant. No structural change has occurred in the tax-benefit system between 1994 and 1998 so that there is no inconsistency between the simulated system of 1998 and observed behaviors (see Bargain and Terraz, 2003). We select a sample of married couples in which adult members are in the age bracket $25-64$ and available for the labor market. For this purpose, households with adults being disabled, retired or being students are excluded. So are households where adults are self-employed since the latter are subject to

\footnotetext{
${ }^{24} \mathrm{~A}$ collective model of labor supply with domestic production poses a host of theoretical and empirical problems as discussed in Apps and Rees (1997) and Chiappori (1997). However, recent and important findings from Donni (2004b) show that (i) simple functional forms which are consistent with the traditional collective model of labor supply can sometimes be compatible with more sophisticated models incorporating domestic production, (ii) if the domestic good is marketable, these models can be tested and partially identified using traditional household surveys (i.e. without resort to time allocation surveys).

${ }^{25}$ It is can easily be shown that the choice of parameters $T_{f}$ and $T_{m}$ does not affect the relative productive efforts across the sample. This way, these parameters are chosen in order to rescale the distribution of efforts so that mean effort coincides with mean hour.
} 
substantially different income tax rules compared to salary workers, requiring additional information not available here.

Extreme households are selected out, notably those receiving important levels of non-labor income and those with more than 3 children or where children earn substantial earnings. Households with more than two decision-makers (other adults than the basic couple) are also discarded. In a pure supply-side logic, we take out households in which adults are unemployed, that is, constrained by the demand-side. Finally, inactive couples are too few in the selected data. So are one-earner couples where only the women is working. These two categories are therefore taken out of the final sample. Eventually, our selection contains 2, 044 households.

\subsection{Inversion of the Collective Model}

\subsubsection{Stochastic Corrections and Convexification of the Budget Set}

As in traditional literature on labor supply estimation, we correct observed behaviors (individual earnings) for various types of errors. ${ }^{26}$ These may correspond to some unobserved heterogeneity in preferences especially as preference parameters are taken homogenous across households in our setting - or accounts for possible measurement errors. More importantly, the stochastic correction solves anomalies in observed behaviors which can be interpreted as optimization errors or errors due to transitory aspects, as we may observe households in-between two static optima. Consequently, we simply add a continuous random disturbance on the distribution of observed incomes. We then add a continuous error term to labor incomes as follows:

$$
y_{h}^{*}=y_{h}^{o b s}+u_{h},
$$

with the natural restriction $y_{h}^{o b s}+u_{h} \geq 0$. The random term $u_{h}$ is assumed independently and identically distributed for all households and drawn from a normal distribution with zero mean and variance $\sigma^{2}$. Our objective is that after correction, all the households observed in some non-convex part of the budget constraint are 'taken out' from this region. In particular, low-wage households working for low earnings and entitled to social assistance do not seem to make a rational choice since they could receive the same level of disposable income without working at all. After correction, their income then falls to zero (they are purely on welfare) or is increased sufficiently to take them out of the non-convexity, at a point where a tangency with the household indifference curve is possible. This way, corrected incomes $y^{*}$ are perfectly consistent with statically optimizing behaviors. Practically, we draw repetitively until obtaining a set of residuals $\left(u_{h}\right)_{(h=1, \ldots H)}$ with minimum variance $\sigma^{2}$ such that all 'irrational' behaviors have disappeared in the population.

Other non-convexities might appear in budget sets, generally created by means-tested transfers to families with children (Complément Familial, Allocation Pour Jeunes Enfants), which concern $17 \%$ of our sample. ${ }^{27}$ Budget sets are reconvexified by replacing the means-test by a linear extension of the transfer up to the next kink on the budget curve. In our selected sample and at the points where households are located, household 'convexified' disposable income never exceeds the initial budget constraint by more than $4.2 \%$ (2.7\% in $90 \%$ of the cases). This is the order of magnitude found in similar approaches of Bourguignon and Magnac (1990) and Moreau and Donni (2002) for France.

The overall result is illustrated in Figure 1. The horizontal axis represents gross income while the vertical axis shows the corresponding level of consumption. The black curve represent the actual budget

\footnotetext{
${ }^{26}$ See Hausman $(1981,1985)$ or Bourguignon and Magnac (1990) for France.

${ }^{27}$ French child benefits are described by Bourguignon and Magnac (1990) and Moreau and Donni (2002).
} 


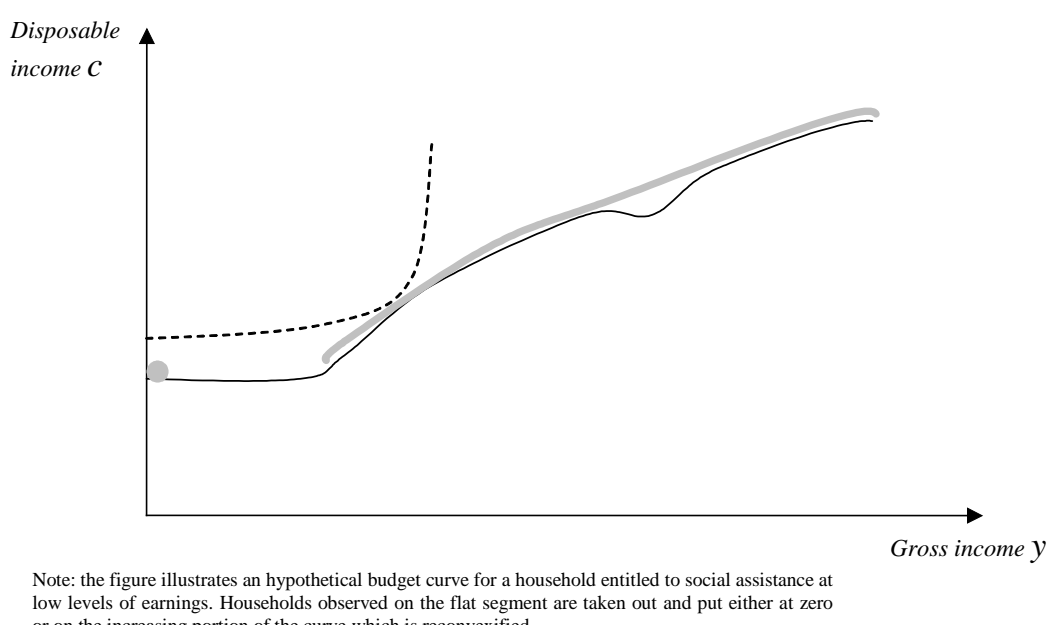

or on the increasing portion of the curve which is reconvexified.

Figure 1: Budget curve: reconvexification and stochastic corrections

constraint, typical to the French tax-benefit system, and the grey curve the region where households are located after stochastic correction of incomes and reconvexification of budget sets. This zone consists of two parts. The first one is a simple point at zero which corresponds to the households living fully on welfare. The second one is the reconvexified part of the budget constraint, beyond the minimum income entitlement region. A household located on this second portion is represented by an indifference curve, indicated by dotted lines. Note that things are naturally more complex in our framework since the horizontal axis is in reality a $\left(y_{f}, y_{m}\right)$ plane.

\subsubsection{Inversion of the Optimal Collective Program: Principle}

We now describe the way to retrieve individual productivity compatible with observed earnings and with the assumption that households are efficient (collective rationality). We simply give the principle of the inversion of the optimal household program in the case of interior solutions (i.e. for two-earner couples). In the Appendices, we describe the analytical solution of the inversion using specific functional forms introduced earlier for both interior and corner solutions.

Primarily, two modifications of the household program are made to simplify the presentation. Firstly, two-earner households are located on the convex envelope of the budget set, represented by the grey curve in Figure 1, so that budget constraints can be linearized locally (at the point of observation). In this respect, we compute the effective marginal tax rates (EMTRs) as follows:

$$
t_{i}\left(y_{f}, y_{m}, Z\right)=1-\frac{\partial g\left(y_{f}, y_{m}, Z\right)}{\partial y_{i}},
$$

which gives implicit productivity $\widetilde{\omega}_{i}=\left(1-t_{i}\right) \omega_{i}$ for spouse $i=f, m$. Also, it is possible to rewrite individual utilities as follows:

$$
\begin{aligned}
U_{i}\left(c_{i}, e_{i}, e_{j}\right) & =U_{i}\left(c_{i}, \frac{y_{i}}{\omega_{i}}, \frac{y_{j}}{\omega_{j}}\right) \quad \text { for } i, j=f, m \\
& =u_{i}\left(c_{i}, y_{i}, y_{j} ; \omega_{i}, \omega_{j}\right) \quad \text { for } i, j=f, m,
\end{aligned}
$$

so that conditionally on the partner's earnings $y_{j}$, preferences of individual $i$ can be represented in the same $\left(y_{i}, c_{i}\right)$ plane as the budget curve. 
With these modifications and for local values of the EMTRs, the optimal program becomes:

$$
\begin{gathered}
\operatorname{Max}_{c_{f}, c_{m}, y_{f}, y_{m}} \mu\left(\omega_{f}, \omega_{m}\right) u_{f}\left(c_{f}, y_{f}, y_{m} ; \omega_{f}, \omega_{m}\right)+\left(1-\mu\left(\omega_{f}, \omega_{m}\right)\right) u_{m}\left(c_{m}, y_{m}, y_{f} ; \omega_{m}, \omega_{f}\right) \\
\text { s.c. } \quad c=c_{f}+c_{m} \leq\left(1-t_{f}\right) y_{f}+\left(1-t_{m}\right) y_{m}+\widetilde{y}_{0},
\end{gathered}
$$

with $\widetilde{y}_{0}$ the virtual non-earned income. First-order conditions lead to marshallian functions of the form:

$$
\begin{aligned}
y_{f} & =\Upsilon_{f}\left(\omega_{f}, \omega_{m}, t_{f}, t_{m}, \widetilde{y}_{0}\right) \\
y_{m} & =\Upsilon_{m}\left(\omega_{f}, \omega_{m}, t_{f}, t_{m}, \widetilde{y}_{0}\right) \\
c & =c_{f}\left(\omega_{f}, \omega_{m}, t_{f}, t_{m}, \widetilde{y}_{0}\right)+c_{m}\left(\omega_{f}, \omega_{m}, t_{f}, t_{m}, \widetilde{y}_{0}\right) .
\end{aligned}
$$

Assume that the last equation can be inverted to give an expression of the virtual non-labor income which is substituted into the two first equations so that:

$$
\begin{aligned}
y_{f} & =Y_{f}\left(\omega_{f}, \omega_{m}, t_{f}, t_{m}, c\right) \\
y_{m} & =Y_{m}\left(\omega_{f}, \omega_{m}, t_{f}, t_{m}, c\right) .
\end{aligned}
$$

Finally, assume that this system can be inverted to retrieve productivities for $i=f, m$ and that the solution is unique. We obtain the following individual abilities:

$$
\begin{aligned}
& \omega_{f}=\Omega_{f}\left(y_{f}^{*}, y_{m}^{*}, c^{*}, t_{f}^{*}, t_{m}^{*}\right) \\
& \omega_{m}=\Omega_{m}\left(y_{f}^{*}, y_{m}^{*}, c^{*}, t_{f}^{*}, t_{m}^{*}\right),
\end{aligned}
$$

evaluated at observed values of labor incomes $y_{f}^{*}$ and $y_{m}^{*}$, total consumption $c^{*}=g\left(y_{f}^{*}, y_{m}^{*}, Z\right)$, and effective marginal tax rates $t_{i}^{*}=t_{i}\left(y_{f}^{*}, y_{m}^{*}, Z\right)$. The French tax-benefit microsimulation program SYSIFF98 allows computing total consumption (disposable income) as well as effective marginal tax rates, by differentiation of the budget constraint at observed locations (see Bargain and Terraz, 2003).

To discuss previous assumptions, consider primarily the case of individuals rather than couples, maintaining the assumption that all have the same preferences and differ only with respect to their productivity. When ignoring other incomes and taxation, the previous principle then simply consists of inverting the expression $y=Y(\omega)$. In this extremely restrictive case, inversion is possible and unique if and only if income is an monotonic function of productivity. In the absence of taxation, a more productive agent will accomplish a productive effort leading to a higher income. This does not mean that the productive effort itself must increase with productivity, and backward bending effort supplies are allowed. This condition is usual in the optimal taxation literature and requires that in the $(y, c)$ plane, the indifference curve of a more productive agent is flatter, or, in other words, that the marginal rate of substitution between consumption and gross income should decrease with the productivity level. ${ }^{28}$ Agents with different productivities will choose different $(y, c)$ couples so that individual income acts as a self-selection device and reveals the level of exogenous productivity of each agent. This must be true also in the presence of taxation and woud require the budget constraint to be smooth to avoid bunching of agents at kink points.

In principle, the theorem of implicit functions could allow us to characterize the Spence-Mirrlees condition in the present case. The problem is however much more complicated since (i) other sources of

\footnotetext{
${ }^{28} \mathrm{~A}$ more productive agent requires less compensation (through a consumption rise) to an increase of gross income since she produces the additional income with a smaller effort. This condition is known under several names (Spence-Mirrlees condition, single-crossing property, agent monotonicity). See Tuomala (1990).
} 
heterogeneity appear (non-labor income), (ii) the problem is in two dimensions as we look at couples, and (iii) 'household preferences' depend on productivities via the Pareto weights. Consequently, we do not search to characterize this condition in the most general case and simply show that with the simple functional forms introduced earlier, inversion is feasible analytically and leads to a unique condition (see Appendices $).{ }^{29}$

\subsubsection{Preference Parameters}

Specifications used in the optimal tax literature are usually very simple. Studies often resort to the quasilinear form - linear in consumption - in which the unique parameters is the wage-elasticity of labor supply. This term can be made to vary in a range between 0 and 1 for a sensitivity analysis of the results with respect to the level of responsiveness of labor supply (see Spadaro, 1999). This specification is useful but presents a major drawback in the present case as it would lead to an equal sharing of total consumption between spouses. The specification in equation (5) is more flexible while keeping a small number of parameters to be chosen. Parameters are homogenous across households but consumptionleisure preferences are chosen to be gender-specific as described below.

Two sets of parameters are chosen arbitrarily but with respect to a certain number of criteria which actually restrict considerably the scope of possibilities. Firstly, parameters must not lead to an implausible distribution of the power index. Secondly, we impose usual regularity conditions on individual utilities. With the functional form at use, monotonicity and concavity conditions imply that the coefficients are positive. In addition, we impose that the three coefficients $\beta^{c}, \beta^{l}$, and $\delta$ sum up to unity for each spouse. This normalization conforms to the necessity to make individual utilities comparable for the sake of the following social welfare evaluation. Thirdly, we assume that $\beta_{f}^{l}>\beta_{m}^{l}$ in order to obtain larger wageelasticities for married women, a well-known fact in the labor supply literature. ${ }^{30}$ Fourthly, homogenous parameters in the selected population must be chosen in a range which allows couples to choose optimally between interior and corner solutions. ${ }^{31}$ Lastly and most importantly, the two sets of parameters are chosen to give two values of the average wage-elasticity (or productivity-elasticity, should we say), which represent the lower and upper bounds of the range of values usually established in the literature. This way, we can analyze the sensitivity of our results to the order of magnitude of the productive effort responsiveness. The two sets of parameters are presented in Figure 2.

\subsubsection{Elasticities}

Elasticities are computed using previous sets of parameters, postulated specifications, and exogenous productivities resulting from the calibrated procedure and described in what follows. The complexity of the tax-benefit system deters us from searching analytical expressions for wage-elasticities and we resort to numerical calculations which simply consist in increasing uniformly female (resp. male) productivities by $1 \%$ to simulate corresponding variations in the supply of productive effort.

\footnotetext{
${ }^{29}$ Note, however, that when ignoring point (i) and assuming fixed correlation between male and female productivities, as done in Boskin and Sheshinski (1983), multidimensionality disappears and it becomes easy to show that for the specific functional forms of the paper, the extended Spence-Mirrlees condition is respected.

${ }^{30}$ Other reasons explain why labor supply of married women is more elastic than for men and in particular the lower level of working hours. Larger elasticities compared to single women is also due to the presence of children, an aspect which is accounted for in the minimum consumption term $\underline{c}_{i}\left(Z_{h}\right)$.

${ }^{31}$ For couples actually observed at corner solutions (one-earner couples), additional conditions are actually imposed during the process of calibrating productivities (see Appendices) and those conditions are only respected for a subset of values of the preference parameters, once all previous conditions are already accounted for.
} 


\begin{tabular}{cccccc}
\hline \hline $\begin{array}{c}\text { Preference } \\
\text { regime }\end{array}$ & \multicolumn{2}{c}{ male } & \multicolumn{2}{c}{ female } & joint \\
& $\beta c$ & $\beta I$ & $\beta c$ & $\beta I$ & $\delta$ \\
\hline$I$ & 0.8 & 0.1 & 0.65 & 0.25 & 0.1 \\
$I I$ & 0.65 & 0.2 & 0.5 & 0.35 & 0.15 \\
\hline
\end{tabular}

Figure 2: Preference parameters

\begin{tabular}{|c|c|c|c|c|}
\hline \multirow{2}{*}{$\begin{array}{l}\text { preference regime } \\
\text { constant } \mu\end{array}$} & \multicolumn{2}{|c|}{$\begin{array}{c}\text { I } \\
\text { (high elasticity) }\end{array}$} & \multicolumn{2}{|c|}{$\begin{array}{c}\text { II } \\
\text { (low elasticity) }\end{array}$} \\
\hline & male & female & male & female \\
\hline \multicolumn{5}{|l|}{$1 \%$ increase in } \\
\hline male productivities & $0,29 \%$ & $-0,46 \%$ & $0,14 \%$ & $-0,26 \%$ \\
\hline $\begin{array}{l}\text { female productivities } \\
\text { variable } \mu\end{array}$ & $-0,14 \%$ & $0,79 \%$ & $-0,07 \%$ & $0,41 \%$ \\
\hline \multicolumn{5}{|l|}{$1 \%$ increase in } \\
\hline male productivities & $0,26 \%$ & $-0,23 \%$ & $0,15 \%$ & $-0,12 \%$ \\
\hline female productivities & $-0,11 \%$ & $0,58 \%$ & $-0,09 \%$ & $0,26 \%$ \\
\hline
\end{tabular}

Figure 3: Productive effort elasticities

In the Appendices, we describe the algorithm used to simulate productive effort supplies using calibrated productivities and the tax-benefit microsimulation program. This algorithm allows simulating the effect of any type of exogenous shock on the budget constraint (e.g. an increase in productivity or a tax reform). It relies on a discrete approach so that computed elasticities account simultaneously for variations at the intensive and extensive margin.

Figure 3 presents the average levels of elasticity obtained with the two different regimes of preferences. As previously mentioned, these regimes have been chosen in order to obtain lower and upper bounds of wage-elasticities. It results that (i) own-wage elasticities indeed give reasonable bounds in line with the existing literature, with a larger order of magnitude for married women, (ii) crossed-wage elasticities are smaller than own-wage elasticities (cf. Blundell et MaCurdy, 2000).

In addition, Figure 3 allows breaking down the effects of rise in productivity. In the upper part of the table, we represent elasticities computed for a constant index $\mu$; only traditional substitution and income effects come into play. In the lower part, elasticities also account for the impact of an increased productivity of one of the spouses on Pareto weights, that is, a distribution effect within the household. For regime $I$ (high elasticities), average own-wage elasticity for female is 0.79 and falls down to 0.58 when $\mu$ is allowed to vary with the increase in the wives' productivities. The explanation is simple. Married women uniformly gain bargaining power so that households tend to value female leisure slightly more, which counter partially the usual positive effect of an increased productivity on female effort supply. ${ }^{32}$ This distributive effect influences mainly participation and is not strong enough to encourage men to stop working so that there is hardly any difference between the two types of elasticities (with and without a constant $\mu$ ) for men.

\footnotetext{
${ }^{32}$ This can be interpreted very easily in the decentralized version of the collective model with an interpretation in terms of sharing rule (cf. Chiappori, 1992). The increase in productivity corresponds to an increase in the implicit transfer in favor of the spouse in the sharing rule, that is, an additional negative income effect on her effort supply.
} 


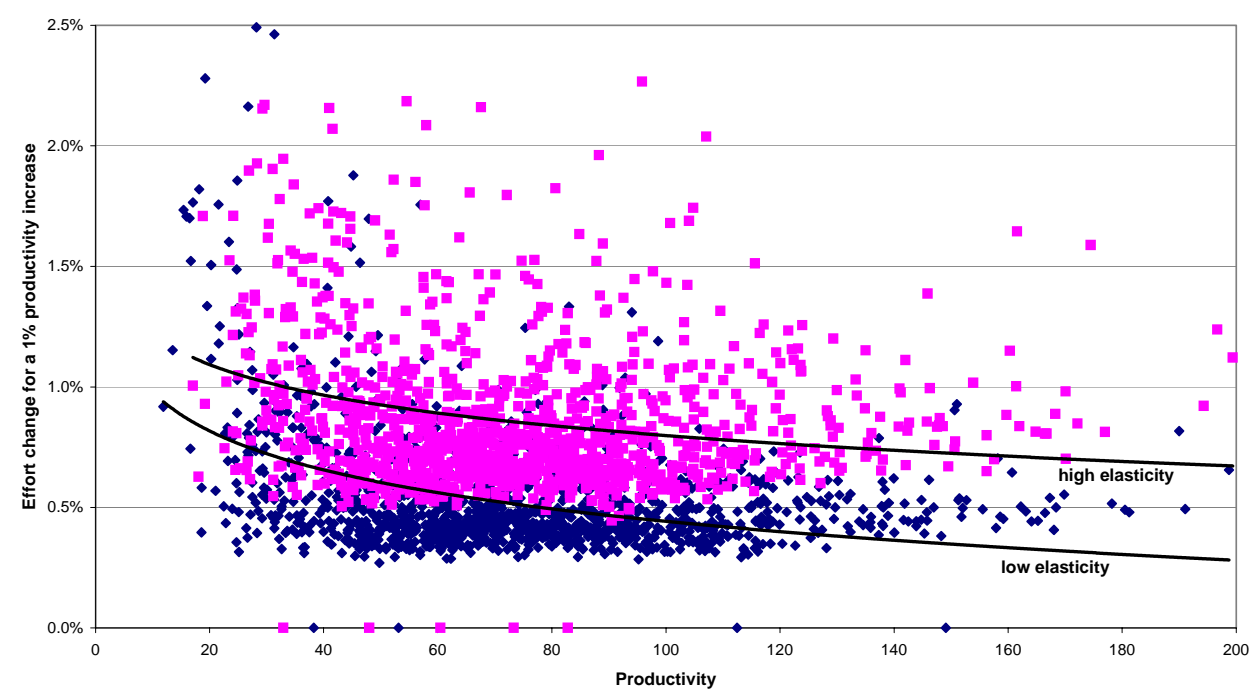

Note: this graph depicts the distribution of women's elasticites according to their level of productivity. The upper (resp. lower) observations corresponds to the assumption of high (resp. low) elasticity and the black curves give the trend in each case.

Figure 4: Productive effort elasticities according to the level of productivity (wives)

Beyond average values, the distributions of individual elasticities are meaningful and we represent the distribution for women in function of the productivity level and for each regime of preference (Figure 4). Trend curves indicate that elasticities tend to diminish with the level of productive ability. This characteristic is in line with the literature (see the discussion in Immervoll et al., 2003) and our model avoids the restrictive assumption of isoelasticity often retained in recent applications and for instance in Spadaro (2004).

\subsection{Results of the Calibration}

\subsubsection{Revealed Productivities}

Figure 5 presents the distribution of productivities obtained for active men and women and in each case, for the two different levels of elasticity. Looking at numerical simulation of the optimal taxation model, Stern (1976) recalls that the distribution of incomes must be somehow different from the distribution of productivities. This aspect is not strongly marked here, in particular for low elasticities. In effect, it is easy to show that the difference of height between the two curves is all the smaller as the effort supply responds less to productivity increases. To illustrate this point, recall that the relation between these two variables is simply $y=\omega e(\omega)$, when ignoring other determinants of the effort supply function $e$. Take the polar case where productive effort is completely inelastic to productivity and assume identical effort functions for all (close to our exercise since we have assumed homogenous preferences), so that $e(\omega)$ is a constant. In this case, we would have:

$$
\frac{y}{E(y)}=\frac{\omega}{E(\omega)}
$$

and the two distributions in Figure 5, expressed in proportion of the sample average, would be exactly the same. 

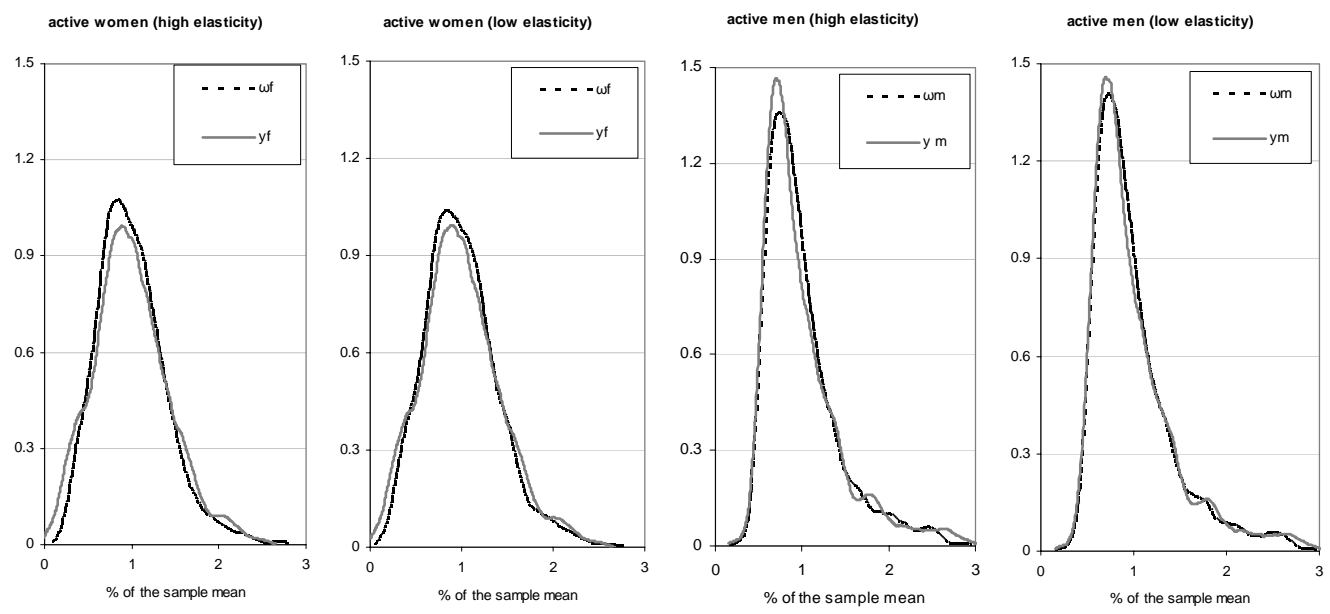

Figure 5: Distributions of incomes $(y)$ and exogenous productivities $(\omega)$

Female own-wage elasticities are all positive in our sample so that productive effort supply increases with the level of productivity. In this case, the distribution of incomes must be less equal than the distribution of productivities, all the more so as elasticities are large. This is in effect what we find in Figure 5. The reverse is true for men as the distribution of incomes is more equal than the distribution of productivities, due to the fact that effort supply is backward bending for a certain number of male individuals.

In Spadaro (2004), the distribution of incomes is truncated at the bottom since labor incomes are censored by stochastic corrections as described earlier. For inactive individuals, it is possible to retrieve analytically a reservation productivity $\bar{\omega}$ and, under several assumptions on the distribution of low productivities, draw values with an upper bound $\bar{\omega}$. In the present exercise, the inversion procedure for corner solutions concerns one-earner couples and attributes a random productivity to the inactive spouse as described in the Appendices. ${ }^{33}$

For two-earner couples, it is possible that the second-earner - most often the wife - generates a very small amount of labor income, which leads to a relatively smaller level of productivity, and explains why distributions are more symmetrical for women than for men. ${ }^{34}$

Average male productivity is 13.3 , average productivity for active female is 11.1 and average productivity for inactive female is 8.7, expressed in euros per unit of effective unit of labor. The two former figures correspond roughly to the average wage rates (in euros per hour) since we have assumed that working time and productive effort must coincide on average. Note also that the correlation rate between calibrated productivities and wage rates is $60 \%$ (resp. 57\%) for women and $84 \%$ (resp. $87 \%$ ) for men in the case of high (resp. low) elasticities.

Figure 6 represents the distribution of Pareto weights on female utilities (i.e. female power indices), computed using expression (4) and calibrated productivities. The mode is close to 0.5 but the distribution

\footnotetext{
${ }^{33}$ The same type of procedure could be used for inactive couples but they are very few in the selected data and are simply taken out of the final sample.

${ }^{34}$ With the restrictive set-up retained here, the whole scope of behaviors cannot be represented and in particular the case of powerful wives who work less or do not work. By construction, this case would imply that these women have high productivities so that prevailing usual substitution effects would convey them to work.
} 


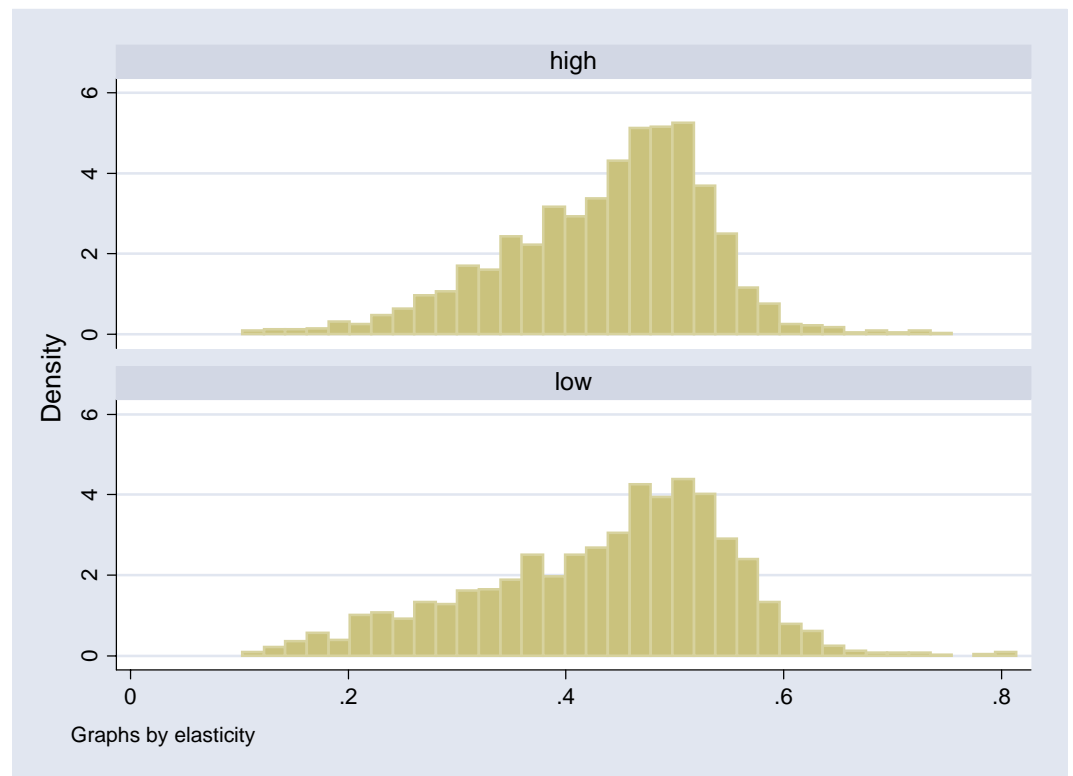

Figure 6: Distribution of Pareto weights

is skewed on the left hand side due to inactive women whose productivities are relatively smaller. In a scenario of high (resp. low) elasticities, the index $\mu$ is $37 \%$ on average (resp. 33.7\%) for one-earner couples and $45.5 \%$ (46\%) for two-earner couples.

\subsubsection{Working Hours versus Productive Effort}

Figure 7 presents the distribution of male productive efforts $\left(e_{m}\right)$ resulting from calibrated productivities and observed earnings, respectively for high and low regimes of elasticities. It is compared to the distribution of work hours $\left(h_{m}\right)$ observed in the data. Under the simple structural assumptions made in our exercise and the postulate that households take efficient decisions, it appears that productive behaviors compatible with observed labor incomes are much less concentrated than work duration. Efforts are not expressed in hours but in some effective units of labor ('effective hours'). Nonetheless, distributions of working hours and productive efforts are represented with the same horizontal axis as we have rescaled efforts so that their average equates the mean hour. The modes of the two distributions is also very close.

The same result is obtained for women in Figure 8. Working hours are highly concentrated around full time (39 hours per week), part time (20 hours) and three-quarter of full time (30 hours), translating the institutional and demand-side rigidities typical to the French labor market. Conversely, the distribution of productive efforts is more continuous and spread, expressing a larger variety of productive behaviors consistent with observed earnings and postulated rationality.

\subsubsection{Inter- and Intra-household Distributions}

The graphs of Figure 9 represent the share of total consumption received by women on average per decile (upper graph) and centile (lower graph). ${ }^{35}$ Comparing these graphs indicates a large intra-decile variance.

\footnotetext{
${ }^{35}$ Quantiles correspond to the distribution of labor income in the selected population. Results do not change dramatically if we consider the distribution of disposable income instead.
} 


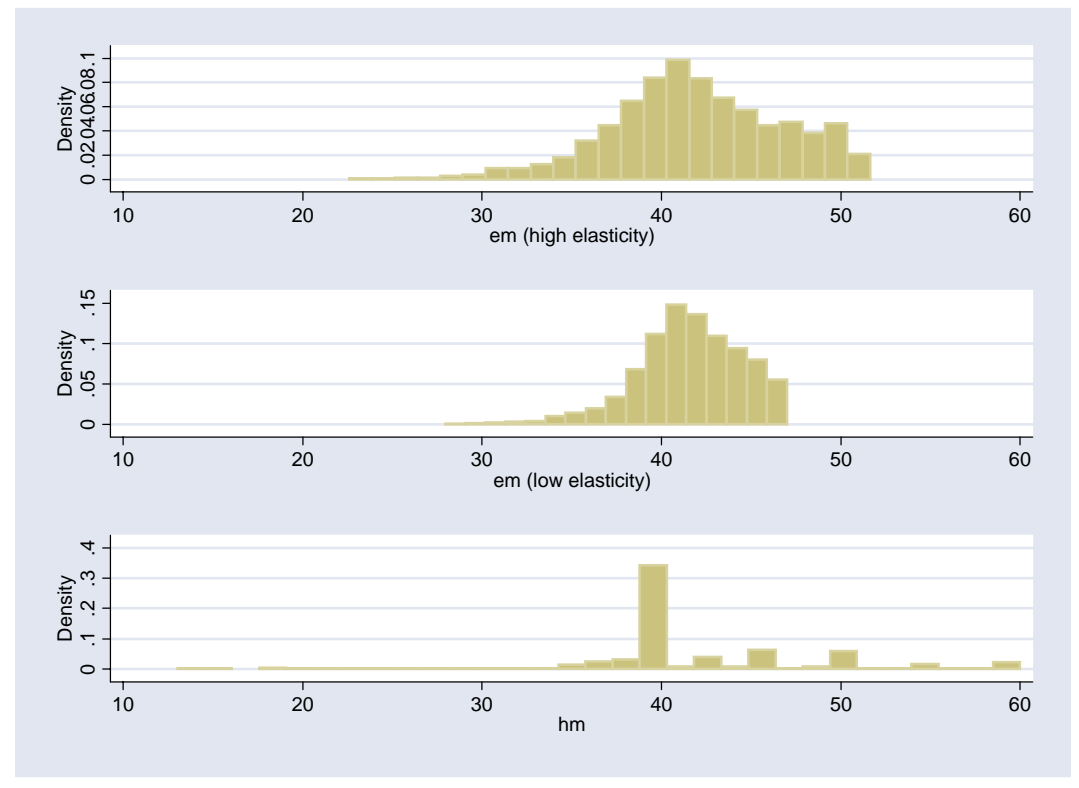

Figure 7: Distributions of working hours and productive efforts (men)

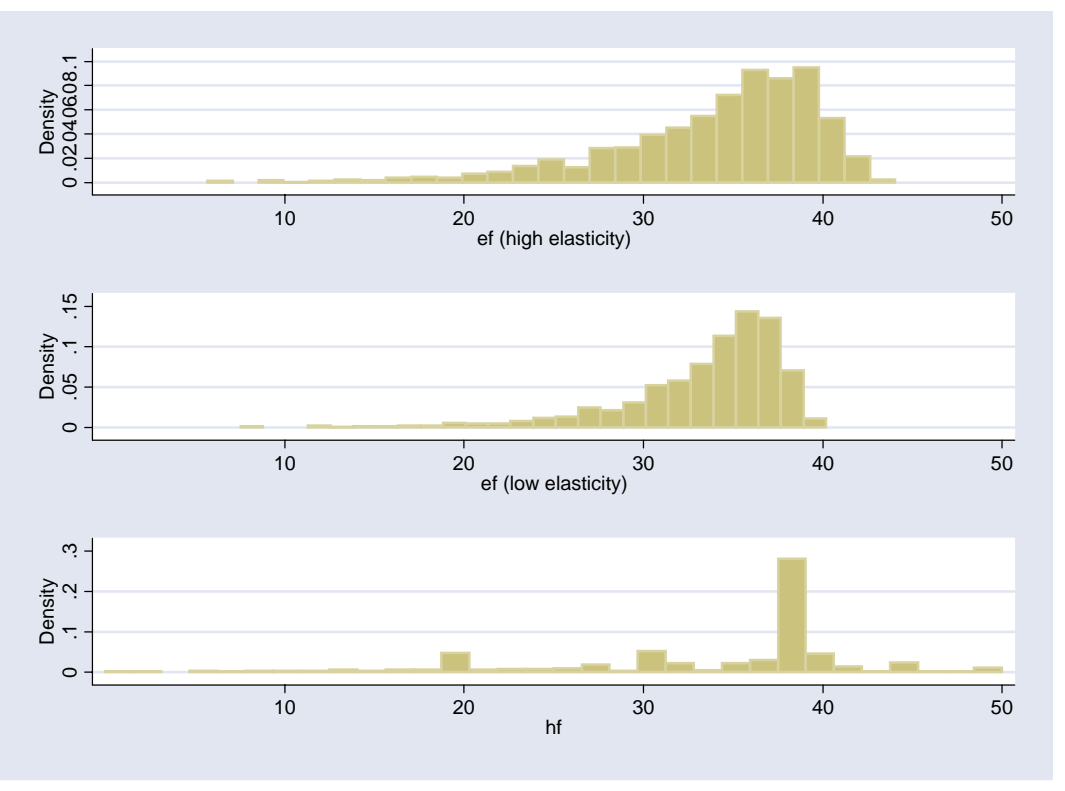

Figure 8: Distributions of working hours and productive efforts (women) 
Nevertheless, it appears that the poorest and the richest households tend to be less egalitarian in terms of intra-household distribution of resources. This result is naturally conditional on previous assumptions but relates to them in a consistent and intuitive way.

Firstly, wives' productivities in poorer households are relatively lower than husbands' insofar as these women are more often inactive, as shown by the average female participation rate per decile (grey curve in the upper graph and right hand side axis). As the consumption sharing depends directly on the bargaining rule (see the explicit expression (19) in the Appendices), itself a function of the ratio of spouses' productivities, it tends to be in favor of husbands in poorer households.

Secondly, both graphs show that inequality in resource sharing is not monotonous with the household level of income since the female share decreases from the 8th deciles onward. This can be explained in part by a cohort effect since richer incomes correspond to older households while it is well-known that the gender gap in earnings increases with age. Note finally that within each decile, the differences between high and low elasticities may be important, a consequence of the preceding results in the distribution of productivities.

The grey curve in the lower graph (and the right hand side axis) represents the average ratio $U_{f} / U_{m}$ per centile, utilities being rescaled by the average value for women and men respectively in order to neutralize the recurrent differences of cardinalization that might remain between female and male measures of welfare. It turns out that this average welfare ratio varies closely around 1 while following the same trend as the consumption sharing. It is noticeable, however, that even if the sharing is fairly unequal for low income households (only between 30 and $35 \%$ of the total consumption goes to the wife on average in the first two deciles), the repartition of welfare is not as uneven since the ratio always remains close to 1 and even exceed 1 from the 3rd to the 9th decile. Naturally, this comes from the fact that women are compensated by a higher level of leisure. Yet, non market time can also correspond to domestic production, which generates additional goods but possibly some disutility for the wife. ${ }^{36}$ This means that we somehow understate welfare inequalities between men and women. This point can only accentuate the conclusions of the next section, related to the possible bias committed in the normative analysis when individual rather than household welfare is accounted for.

Following Haddad and Kanbur (1990), we now study to which extent the levels of income inequality are understated when intra-household inequalities are ignored. Denote $c_{h}$ the average consumption in household $h=1, . . H$ and $c_{n}$ the individual consumption of individual $n=1, . . N$ in the population, considering as previously that each household is exactly composed of two consumers (children are internalized in the parents' preferences). We then have $N=2 H$ and the average values of $c_{h}$ and $c_{n}$ are equal. We use the most basic measure of inequality, the variance, so that inequality can be decomposed in a straightforward way into two components:

$$
V\left(c_{n}\right)=V\left(c_{h}\right)+\frac{1}{H} \sum_{h} V\left(c_{n} / c_{h}\right)
$$

The first term represents the inequality across households and the second the intra-household inequality (see Haddad and Kanbur, 1990). Naturally, it is relatively rare to observe individual levels of consumption, as done by Haddad and Kanbur for the Philippines, and the contribution of collective models in our setting is precisely to identify intra-household distribution of resources from the usual aggregated observations.

\footnotetext{
${ }^{36}$ To ignore domestic production is a serious limitation of the labor supply literature but also of the subsequent evaluation in terms of social welfare and its consequences regarding optimal taxation (see Apps and Rees, 1996).
} 

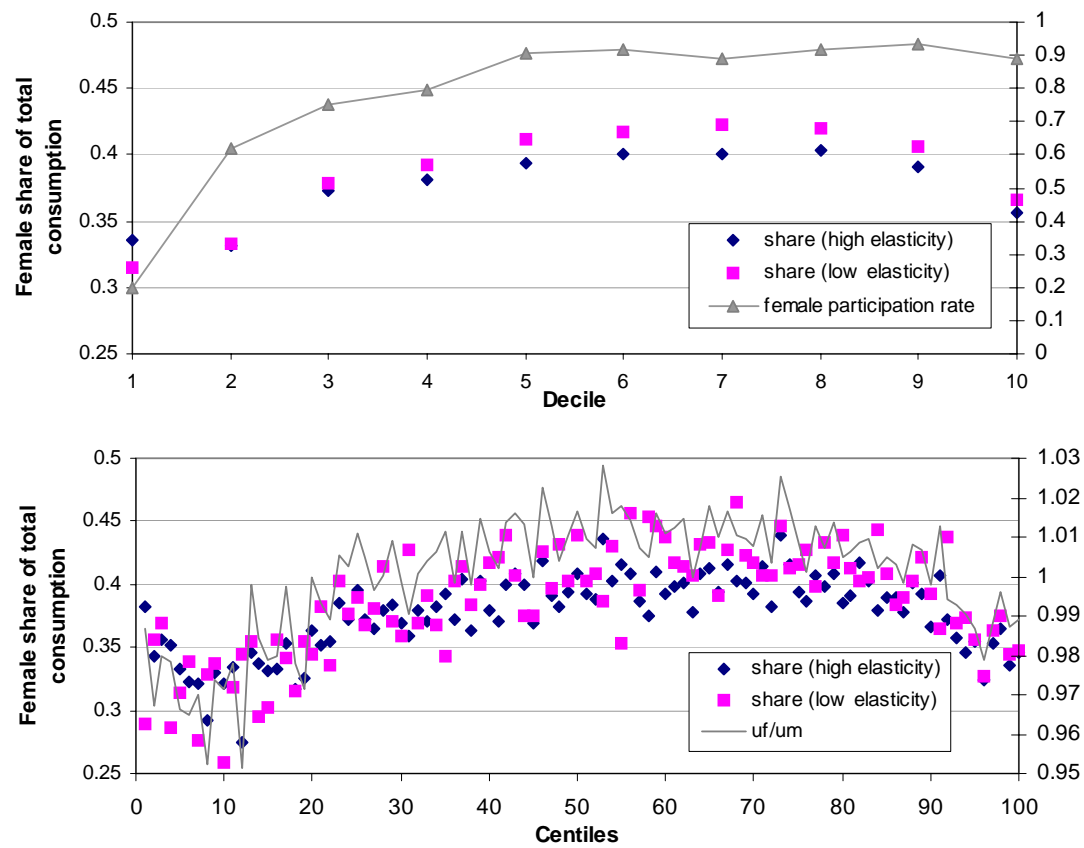

Note: the upper graph depicts the w ife's average share (in \%) of household consumption per decile (left scale) and the female average participation rate (right scale). The low er graph depicts the $w$ ife's average share per centile (left scale) and the average w elfare ratio betw een spouses (right scale), individual utilities being deflated by the population mean

Figure 9: Consumption share of women in the distribution of income in the population

With the assumption of high (resp. low) elasticities, we find that intra-household inequality explains $37.3 \%$ (resp. 37.8\%) of $V\left(c_{n}\right)$. It then turns out that the rudimentary distribution rule postulated in our exercise allows departing substantially but not unreasonably from the equal sharing assumption. Haddad and Kanbur obtain the same order of magnitude when using real individual observations. Yet, it is difficult to compare both studies as the countries under examination are fairly different. More comparable is the recent result from Lise and Seitz (2004) who estimate a collective model on British data and obtain that depending on the year of interest, the level of intra-household inequality represents between a third and a fifth of the total inequality across individuals.

As Haddad and Kanbur (1990) suggest, it can be shown that the neglect of intra-household inequality is not detrimental in certain cases and in particular when studying the pattern of inequality. If we divide our sample in two groups, for instance couples with children $(A)$ and couples without $(B)$, the ranking in terms of inter-individual inequality establishes that group $A$ is more egalitarian than group $B$ while this ranking holds for inter-households inequality. This results from the fact that intra-household inequality is not very different across these two groups. Indeed, it contributes to 36.9 and $38.9 \%$ of inter-individual inequality in group $A$ and $B$ respectively. ${ }^{37}$

\footnotetext{
${ }^{37}$ However, the contribution of inter-group inequality to total inequality in the population is overstated when ignoring intra-household inequality since in this case, intra-group inequalities are overstated.
} 


\section{Reform Simulation and Normative Evaluation}

\subsection{Reform}

The reform we suggest is a simulation of the British Working Family Tax Credit (WFTC) on the selected population of French couples. This reform introduced in the UK in 1999 consists of a tax credit targeted to households with children in which at least one member works for a minimum of 16 hours per week. ${ }^{38}$ The maximum amount of 75 EUR per week is increased by $49 \%$ per dependent child and by $20 \%$ if work duration exceeds 30 hours per week. When earnings are above a threshold of 128 EUR per week, the maximum amount is diminished by $55 \%$ of the net income (i.e., net of tax and social contributions). We extend this reform to all types of households, with and without children. A more precise definition of the reform is given in Bargain and Orsini (2004), as well as the specific modalities retained to adapt the reform to the French tax-benefit system.

\subsection{Incentive and Distributive Effects}

The reform is suspected to have a strong disincentive impact on the second-earner (usually the wife) since her net gain to work may decrease with the introduction of the tax credit. In effect, household disposable income is likely to increase when she does not work through the eligibility via the husbands' salary, while the household may be too rich to be eligible when she works. Consequently, the wife is induced to reduce her effort, the loss of income being compensated by an increase of tax credit and an increase of free time for the wife. This disincentive effect is common to in-work policies when those are conditional on the spouses' joint income. ${ }^{39}$

Bargain and Orsini (2004) reveal that the reform would discourage between 150,000 and 190,000 French married women to work, that is, between 3.8 and $4.8 \%$ of the selected sample of couples in this study. The result is in part driven by the size of average wage-elasticities, between 0.5 and 0.7 according to their sensitivity analysis. Here, the postulated regimes of preferences lead to average wage-elasticities between 0.4 and 0.8. Even if mean elasticities are relatively close in both exercises, the distributions of elasticities are probably significantly different. This comes together with the fact that the present exercise addresses the elasticity of productive effort rather than simple working hours. Overall, we find a relatively larger disincentive effect as it concerns between 5.7 and $8.5 \%$ of the selected population. Male participation does not change but overall, male productive effort decreases by $6 \%$ while female effort decreases by $10.6 \%$ (resp. 3.2 and $7.8 \%$ ) with the high (resp. low) scenario on elasticities.

The disincentive effect implies a drop in labor income, hence in tax revenue, and a rise of the cost of the reform since tax credit transfers increases via the husbands' salaries. To maintain budget neutrality, we have calibrated a consumption tax, which can be seen as a rise of the VAT and is assumed to take effect simultaneously to the introduction of the reform. This specific tax amounts to 4.6 (resp. 3.1) percentage points for the high (resp. low) elasticity regime. These figures might appear fairly high. Nonetheless, it must be kept in mind that the cost is only borne by the population of couples.

The distributive effect of the reform is unambiguous, as illustrated by the upper graph in Figure 10 (left hand side vertical axis). The set of reforms (WFTC and indirect taxation) benefits to the first three deciles of the selected population while the rest of the distribution suffer an increase of net taxes. Yet, the

\footnotetext{
${ }^{38}$ To respect this condition in the simulation, working time is computed using wage rates - observed or predicted for non-participants - and simulated earnings, that is, labor income corresponding to optimal effort supply choices.

${ }^{39}$ See for instance Blundell et al. (2000) for the WFTC and Eissa and Hoynes (2004) for the US Earned Income Tax Credit.
} 

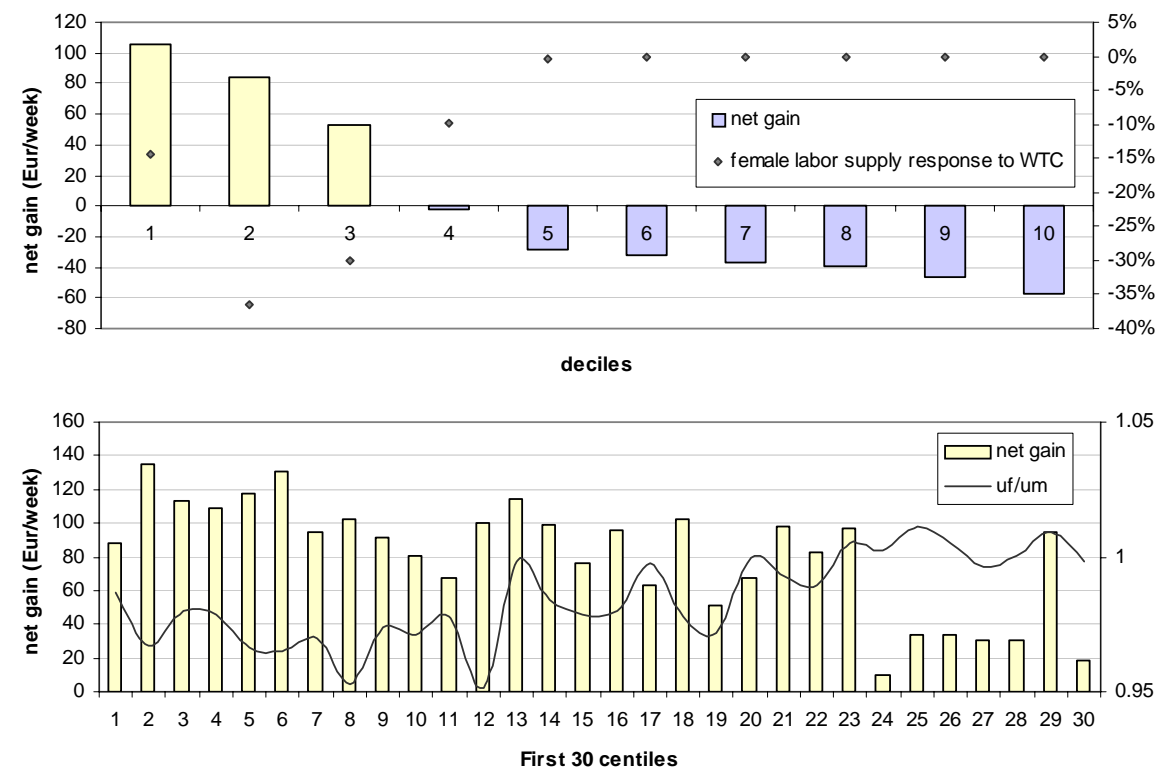

Note: the upper graph show s the average net gain of the combined reforms per decile (left scale) and the average change, in $\%$, due to the WFTC reform. The low er graph depicts the average net gain per centile (left scale) and the post-reform averaqe w elfare ratio per centile (riaht scale). for the 30 first centiles of the distribution.

Figure 10: Distribution of net gains from the reforms

decomposition by deciles of gross income give a crude view of the distribution as it corresponds to average figures per decile. The lower graph in Figure 10 (left hand side vertical axis) breaks the distribution down for the first thirty centiles. It appears that the net gain of the reforms is fairly uniformly spread, at least in the first twenty centiles. This point means that the reform does not specifically target the poorest. ${ }^{40}$

It is also noticeable that the increase in non market time for married women after the reform benefits more to the second decile. This point is illustrated by the average variation of working time specifically due to the WFTC, in the upper graph of Figure 10 (right hand side vertical axis). Overall, the average welfare ratio $U_{f} / U_{m}$ remains higher in the second and third deciles than in the first (lower graph, right hand side vertical axis).

\subsection{Social Welfare Evaluation}

Is the reform desirable according to the inequality criterion? There is a clear transfer from the top half to the bottom of the distribution so that inter-household inequality, previously measured by $V\left(c_{h}\right)$, decreases by $5 \%$. The impact on intra-household inequalities is yet ambiguous. In effect, the richer households main payer of the complete reform - and the poorer household - main beneficiaries - are the two groups in which intra-household inequities are the highest (cf. Figure 9). We find that intra-household inequality decreases by $6.8 \%$ so that its contribution to total inequality decreases by 0.5 percentage points. Overall, inter-individual inequality - the variance $V\left(c_{n}\right)$ - benefits from the reduction of inequality both across and within households and decreases by $5.7 \%$.

\footnotetext{
${ }^{40}$ This result would be accentuated if one considered the whole population since in this case, the first decile would be composed in majority by inactive households - excluded here from the selection - hence non eligible to a WFTC-type reform. Several reports from the Institute of Fiscal Studies indeed show that in the United Kingdom, the WFTC benefits more to deciles 2 to 4 than to the first decile.
} 
Peluso and Trannoy (2004) show that a redistributive transfer is beneficial both in terms of interhousehold and inter-individual inequalities if the sharing rule is increasing and concave with the level of income, that is, if intra-household inequality increases with household wealth. The problem with this type of characterization is that it requires an important degree of homogeneity across households. Actual heterogeneity, however, is unlikely to allow such regularities to occur. In the present exercise, the only heterogeneity in the distribution rule - the fact that Pareto weights depend on individual-specific productivities - lead to a consumption sharing - expression (19) in the Appendices - which is clearly non monotonic as commented earlier and illustrated in Figure 9.

Up to this point, the evaluation of the reform refers to the individual measures of inequality and poverty as in the very few studies which address intra-household issues. We now suggest two extensions. Firstly, previous studies consider only the distribution of resources across individuals or equate individual welfare and consumption. Yet, it is desirable - using additional assumptions - to account for a more comprehensive measure of individual welfare, which might not be proportional to private consumption and depends on other determinants. In what follows, the terms 'distribution' and 'inequality' (or their synonyms) refer to welfare rather than consumption. Secondly, redistributive policies must be addressed together with the means to achieve them, that is, efficiency constraints. Using a Bergson-Samuelson social welfare function as presented in Section 2, we then compute the variation in the level of social welfare before and after the reform, accounting both for behavioral responses (incentive compatibility constraint) and revenue-neutrality (binding budget constraint of the government).

The results are derived for two levels of elasticities and we suggest three measures of social welfare:

$$
\begin{aligned}
S W_{1} & =\frac{1}{1-\gamma} \sum_{h}\left[W_{h}\left(U_{f_{h}}, U_{m_{h}}\right)\right]^{1-\gamma} \\
S W_{2} & =\frac{1}{1-\gamma} \sum_{h}\left[U_{f_{h}}+U_{m_{h}}\right]^{1-\gamma} \\
S W_{3} & =\frac{1}{1-\gamma} \sum_{h}\left[\left(U_{f_{h}}\right)^{1-\gamma}+\left(U_{m_{h}}\right)^{1-\gamma}\right] .
\end{aligned}
$$

The first index $S W_{1}$ corresponds to the usual practice according to which household welfare is the object of concern. In this case, the public planner ignores intra-household distribution rules and must assume an equal sharing in the household. This means that the planner implicitly attributes the same Pareto weights as the household on individual utilities, or, in other words, that the household rule is optimal for the planner. This assumption of 'non-dissonance' between social preferences and 'household preferences' is retained in the rare applications of optimal tax theory applied to couples as these studies are only concerned by efficiency aspects (see Apps and Rees, 1996, 1999).

The second measure $S W_{2}$ drops the non-dissonance hypothesis and attaches equal importance to both spouses' levels of welfare. In this case, social preferences depend on some sort of average utility in the household, which seems as restricted as the average $c_{h}$ we looked at when we were concerned with consumption levels. More fundamentally, this formulation appears somewhat artificial here. Indeed, if the planner is capable of observing intra-household mechanisms, as it is assumed here, there is no reason why he should not target individual welfare and choose directly the third criterion $S W_{3}$. Formulation $S W_{2}$ is then given for purely illustrative purposes, as an intermediate measure between 1 and 3. Finally, $S W_{3}$ is no more than a rewriting of expression (1) and accounts for both inter- and intra-household inequalities. 


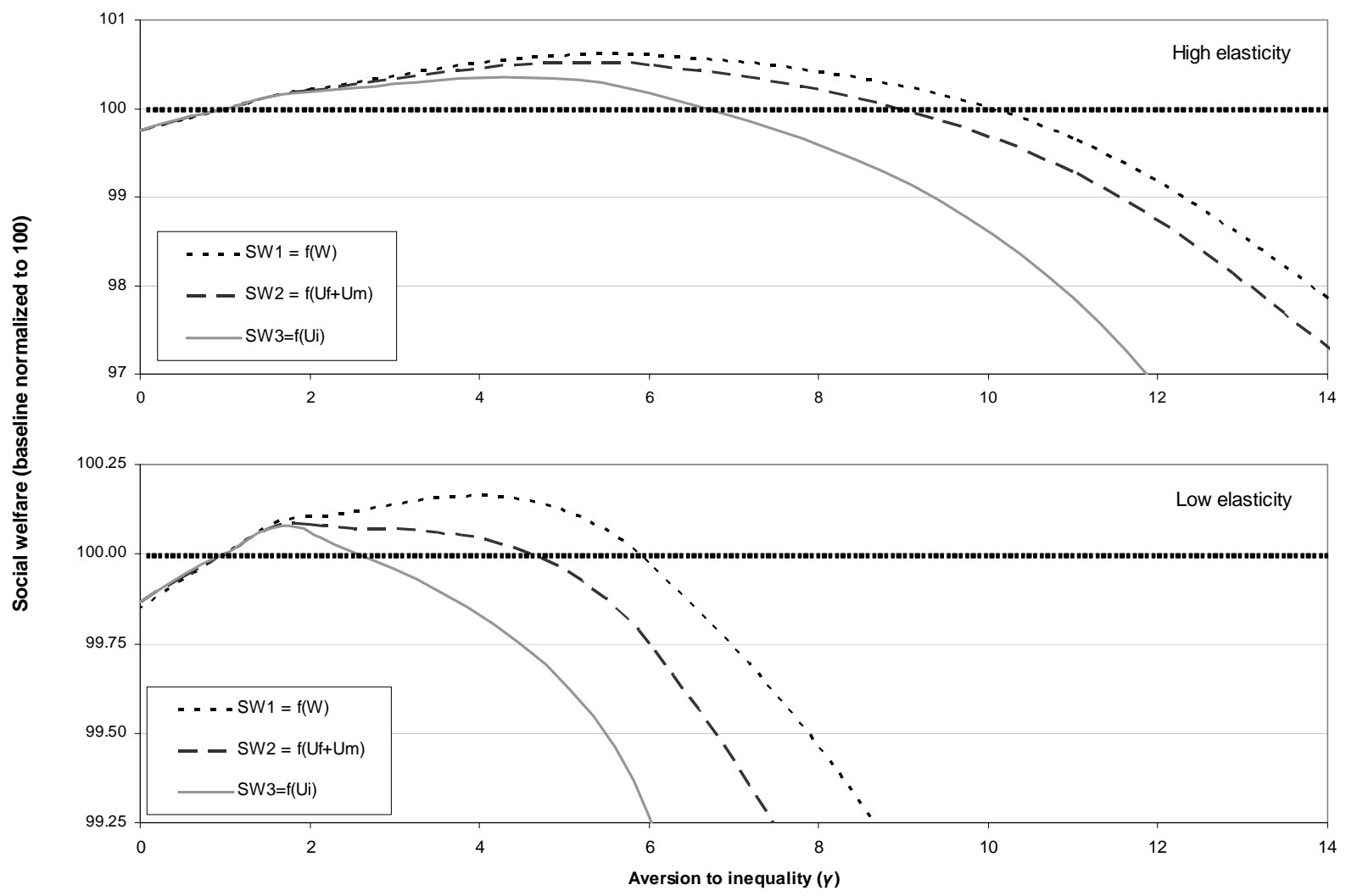

Figure 11: Impact of the reform on social welfare

\subsection{Results}

Figure 11 presents the result of the normative analysis. For each of the three social welfare measures introduced above, each curve represents the level of social welfare after the reform (vertical axis) for different levels of social aversion to inequality (horizontal axis), relatively to the level of pre-reform welfare, normalized to 100 in each case (dotted line).

We first suggest an explanation of the general trend of all three curves. It turns out that for low values of social inequality aversion ( $\gamma$ parameter), the pre-reform situation is socially preferred whatever the measure of welfare. In effect, for utilitarian preferences $(\gamma=0)$ or close to this, only the efficiency criterion matters while the reform generates strong disincentive effects on female labor. As the equity criterion becomes more important (from $\gamma=1$ onward), the reform becomes socially desirable. Finally, as we tend toward rawlsian preferences $(\gamma \rightarrow+\infty)$, the pre-reform situation becomes preferable again since the reform does not specifically target the poorest, as seen before.

Remark that the reform is desirable for a shorter range of $\gamma$ values when low elasticities are assumed. In effect, in this case, the efficiency constraint is slightly relaxed so that the planner needs to be 'a little less rawlsian' to prefer a system in favor of the poorest.

The second important result is related to the fact that the three curves diverge as the equity criterion becomes more important. With the curve corresponding to $S W_{3}$, the range of $\gamma$ values for which the reform is socially desired is substantially shorter. In other words, the degree of inequality aversion 
necessary to reject the reform is lower. This means that social preferences are even more sensitive to the lack of targeting on the first decile when individuals come in consideration. In effect, intra-household inequality is more important in the first decile than in the second (see the welfare ratio $U_{f} / U_{m}$ in lower graphs of Figures 9 and 10). In addition, female leisure increases less in the first decile than in the second after the reform (see upper graph in Figure 9). Overall, the social planner needs to be a little less rawlsian to prefer a pre-reform system when he is concerned with the fate of individuals rather than households.

These results show that the addition of an intra-household distribution concern plays a substantial role in the evaluation in terms of social welfare of this policy change. Divergences may still increase if one considers the likely error committed on the elasticities of productive behaviors. If responsiveness is small and the planner can observe individual welfare, it is sufficient to be little rawlsian ( $\gamma$ slightly below 3$)$ to reject the reform on equity grounds. However, if the true elasticities are in fact high and the planner is not aware of unequal intra-household distributions, the reform will be accepted for $\gamma=3$ or for levels of inequality aversion up to three times higher (i.e., the reform is rejected from $\gamma=10$ onward).

Finally, it is worth mentioning that for other types of tax-benefit reforms, we may obtain different orders of magnitude in the discrepancies coming from the evaluation of household welfare instead individual welfare. Notice, however, that the role of intra-household distribution concerns is significant for the present reform even though the latter does not target individuals but households. One could expect even larger discrepancies in the case of reforms which target one spouse in particular.

\section{Final Discussion}

It seems natural to think that the ultimate object of concern of economic policy in general and taxbenefit policy in particular is the welfare of individuals. Previous studies and notably Haddad and Kanbur (1990) have shown that the levels of inequality across individuals were dramatically understated when inequality across households alone was accounted for, that is, when intra-household inequalities were neglected. In this paper, we suggest to extend these conclusions to the distribution of individual welfare in the normative framework of optimal taxation. This approach naturally requires additional assumptions on the structure of individual preferences and negotiation rules within families.

Instead of deriving the optimal tax schedule consistent with a given level of social inequality aversion, we prefer to simulate the situation before and after a redistributive reform in order to evaluate the range of inequality aversion for which the reform is judged socially acceptable. Then, we abandon the assumption of fair sharing in the household - equal or proportional to individuals' needs - which has prevailed up to now in the literature. For this purpose, we apply the collective model of labor supply calibrated on observed behaviors using French data for couples. More specifically, the social planner is assumed to ignore individual productivities insofar as observed working hours do not reflect the true productive effort underlying observed labor income. Using simple assumptions relative to preferences and the household decision making process, we then invert the optimal household program to retrieve individual productivities consistent with observed individual earnings.

In a second stage, we combine a complete microsimulation of the tax-benefit system in force and the behavioral model to simulate the effects of a tax credit (the British WFTC) on the selected samples of French couples. It is shown that the reform is not desirable if the social planner is either utilitarian (the reform strongly discourage married women with employed partners to work) or rawlsian (the reform does not target specifically the poorest). It is socially acceptable for an intermediate range of values of the social aversion to inequality. The size of this interval depends notably on the level of productive effort 
responsiveness.

More originally, the conclusions of the normative analysis also show that the desirability of the reform varies substantially if the planner is able to infer information about the intra-household distribution, i.e., if the social welfare function is concerned with individual rather than household welfare. This result naturally relies on specific assumptions relative to the form of the intra-household negotiation and individual preferences. The initial objective, however, is to show that the social welfare evaluation is not insensitive to a negotiation rule which departs reasonable from the hypothesis of equal sharing in the household. In future research, these conclusions shall rely on more accurate bargaining rules as techniques to estimate collective models of labor supply with taxation become more robust and more familiar. ${ }^{41}$

Is it so that the normative framework should be extended to individual welfare when it comes to evaluating tax reforms or to derive optimal tax schedules? This essential question has not been addressed in the paper and remains a delicate issue insofar as a unique instrument - taxation - is expected to correct both intra- and inter-household inequities. For instance, should we increase transfers toward a rich but very inegalitarian household in order to improve the living conditions of the poor individual in this household? In an evaluation of the $S W_{2}$ or $S W_{3}$ type, intra- and inter-household distributions certainly interfere in a hazardous way. One might suggest diversifying instruments. Is the shift from a householdbased system (e.g. joint taxation of couples) to a purely individualized system solving the problem? At the moment, redistributive schemes as social assistance or child benefits usually tend to rely on the household while taxation is individualized in some countries. Notice, however, that an individual transfer (resp. tax) toward the poorer (resp. richer) spouse may well be fully neutralized by the household's internal distribution process. ${ }^{42}$

Which instrument may serve a double redistribution in order to maximize the social aggregation of individual welfares? One might think about indirect taxation. In effect, it is possible to tax differently goods consumed by a sub-group (poor households) but also by some individuals (female) in order to achieve our goal. This is however conditional on being able to identify individuals in need and some consumption which is specific to them. Theoretical work on this subject is in its infancy but an important research avenue stands out (see Bargain, Donni, and Marceau, 2004). Overall, it seems wiser to conceive a double redistribution among households and individuals as the result of a larger set of tax and legal instruments. Among other things, taxation can be completed by legislative measures on alimony or divorce rules, which might influence the distribution factors in a specific way (or, equivalently, household members' outside options). ${ }^{43}$

\section{References}

[1] Apps, P.F. and R. Rees (1996): "Labour supply, household production and intra-family welfare distribution", Journal of Public Economics, 60, 199-219.

\footnotetext{
${ }^{41}$ The very first attempt to estimate a collective model with nonlinear taxation is presented in Moreau and Donni (2001).

${ }^{42}$ The debate on the possibility to influence intra-household distribution by targeting tax-benefit instruments toward one spouse or the other is still an open question. Lundberg, Pollak, and Wales (1996) estimate the effects of a reform of the transfers to families with children in the United Kingdom,switching the identity of the recipient from the father to the mother. This wallet to purse transfer within the household is shown to significantly affect the household consumption patterns. The same natural experiment is conducted on Australian data by Bradbury (2002) who does not find any significant effects. Bargain and Moreau (2002) find that the distributive effect specific to taxation - in the case of an individualization of the French income tax scheme - is significant but too small compared to traditional income and substitution effects.

${ }^{43}$ Chiappori, Fortin, and Lacroix (2002) show that a divorce legislation which is less constraining for married women plays a significant role on the sharing rule.
} 
[2] Apps, P.F. and R. Rees (1997): "Collective Labor Supply and Household Production" (Comments), Journal of Political Economy, 105, n 1, 178-190.

[3] Apps, P.F. and R. Rees (1999): "Joint vs. individual taxation in models of household production". Journal of Political Economy, 107, 393-403.

[4] Atkinson, A.B. and J. Stiglitz (1980), Lectures in Public Economics, McGraw Hill.

[5] Bargain, O. and N. Moreau (2002): "Is the collective model of labor supply useful for tax policy analysis? A simulation exercise", Working Paper DELTA.

[6] Bargain, O. and K. Orsini (2004): "In-work policies in Europe: killing two birds with one stone?", working paper EUROMOD.

[7] Bargain, O. and I. Terraz (2003): "Evaluation et mise en perspective des effets incitatifs et redistributifs de la Prime pour l'Emploi.", forthcoming in Economie et Prévision.

[8] Bargain, O., O. Donni and N. Marceau (2004): "Commodity Taxation in Multi-Person Households", mimeo.

[9] Basu, K. (2001): "Gender and Say: A Model of Household Behavior with Endogenously-Determined Balance of Power", mimeo Cornell University.

[10] Beninger, D. and F. Laisney (2002): "Comparison between unitary and collective models of household labor supply with taxation", ZEW Discussion Paper 02-65, ZEW, Mannheim.

[11] Blundell, R.W. and T. MaCurdy (2000): "Labor Supply: A Review of Alternative Approaches", in Ashenfelter and Card (eds), Handbook of Labor Economics, Elsevier North-Holland.

[12] Blundell, R.W. , P.-A. Chiappori, T. Magnac and C. Meghir (2001): "Collective Labour Supply: Heterogeneity and Nonparticipation", mimeo, University College London.

[13] Blundell, R.W., A. Duncan, J. McCrae and C. Meghir (2000): "The Labour Market Impact of the Working Families' Tax Credit", Fiscal Studies, 21, 1, 75-103.

[14] Boskin M. and Sheshinski E. (1983) : "Optimal tax treatment of the family : married couples", Journal of Political Economy, 20, 281-97.

[15] Bourguignon, F. (1999): "The cost of children : may the collective approach to household behavior help ?", Journal of Population Economics.

[16] Bourguignon, F. and T. Magnac (1990): "Labor supply and taxation in France", Journal of Human Resources, 25, 358-389.

[17] Bourguignon, F. and A.Spadaro (2000a): "Redistribution et incitations au travail: une application empirique simple de la fiscalité optimale", Revue Economique, 3, 51.

[18] Bourguignon, F. and A.Spadaro (2000b): "Social preferences revealed through effective marginal rates", working paper DELTA 2000-29.

Bourguignon, F., M. Browning and P.-A. Chappori (1995): "The Collective Approach to Household Behavior", DELTA working paper, 95-04. 
[19] Bradbury, B. (2003): "Consumption and the within-household income distribution: outcomes from an Australian experiment", presented at the CESifo Venice Summer Institute'03.

[20] Browning M. (1992): "Children and Household Economic Behavior", Journal of Economic Literature, vol. $30, \mathrm{n}^{\circ} 3,1434-1475$.

[21] Browning, M. and P.-A. Chiappori (1998): "Efficient Intra-Household Allocations: A General Characterization and Empirical Tests", Econometrica, 66, 1241-1278.

[22] Browning, M., F. Bourguignon, P.-A Chiappori and V. Lechene (1994): "Incomes and Outcomes: a Structural Model of Intra-Household Allocation", Journal of Political Economy, 1994, 1067-97.

[23] Browning M. and V. Lechene (2001): "Caring and Sharing: Tests Between Alternative Models of Intra-household Allocation", Working Paper, Oxford University.

[24] Chiappori, P.-A. (1988): "Rational Household labor Supply ", Econometrica, 56, 63-89.

[25] Chiappori, P.-A. (1992): "Collective labor Supply and Welfare", Journal of Political Economy, 100, 437-467.

[26] Chiappori, P.-A. (1997): "Introducing household production in collective models of labor supply", Journal of Political Economy, 105, 191-209.

[27] Chiappori, P.-A. , R.W. Blundell and C. Meghir (2002): "Collective Labor Supply with Children", IFS working paper, W02/08.

[28] Chiappori, P.-A., B. Fortin and G. Lacroix (2002): "mariage Market, Divorce Legislation and Household Labor Supply", Journal of Political Economy, 110, 37-72.

[29] Choné, P. and G. Laroque (2001): "Optimal incentives for labor force participation", forthcoming in Journal of Public Economics.

[30] Dauphin, A. and B. Fortin (2000): "A Test of Collective Rationality for Multi-Person Households", working paper Université Laval.

[31] Dauphin, A., B. Fortin and G. Lacroix (2002): "A Test of Collective Rationality Within Bigamous Households in Burkina Faso", working paper Université Laval.

[32] Donni, O. (2003): "Collective household labour supply: nonparticipation and income taxation", Journal of Public Economics, 87, 5-6, 1179-1198.

[33] Donni, O. (2004a): "A collective model of household behavior with private and public goods: theory and some evidence from U.S. data", Cahiers de recherche du CIRPEE, 0402.

[34] Donni, O. (2004b): "A note on the collective model of labor supply with domestic production", mimeo.

[35] Eissa, N. and H. Hoynes (2004): "Taxes and the Labor Market Participation of Married Couples: The Earned Income Tax Credit”, Journal of Public Economics, 88, 9-10, 1931-1958.

[36] Feldstein, M. (1995): "The effect of marginal tax rates on taxable income: a panel study of the 1986 Tax Reform At", Journal of Political Economy, 103, 3, 551-572. 
[37] Haddad, L.and R. Kanbur (1990): "How serious is the neglect of intra-household inequality?", Economic Journal, 100, 866-881.

[38] Hagneré C., N. Picard, A. Trannoy and K. Van der Straeten (2002): "La prime pour l'emploi est-elle optimale?", Economie Publique, 11, 15-44.

[39] Hausman, J.A. (1981): "Labor Supply", in How Taxes Affect Economic Behavior, ed.H. Aaron and J.Pechman, The Brookings Institution, Washington D.C., 27-72.

[40] Hausman J.A. (1985): "The Econometrics of Nonlinear Budget Sets", Econometrica, 53, 1255-82.

[41] Heckman, J. (1993): "What has been learned bout labor supply in the past twenty years?", American Economic Review, 83, 2, 116-121.

[42] Immervoll, H., H. J. Kleven, C. T. Kreiner and E. Saez (2003): "Welfare reform in European countries: a microsimulation analysis", EUROMOD working paper.

[43] Kooreman, P. and A. Kapteyn (1990): "On the Implementation of Some Game Theoretic Models of Labor Supply", The Journal of Human Resources, 25, 584-598

[44] Laroque, G. (2002): "Income maintenance and labor force participation", CREST working paper.

[45] Laroque, G. and B. Salanié (2002), Institutions et emploi, le marché du travail des femmes en France, Economica.

[46] Lewbel, A., P.-A. Chiappori and M. Browning (2002): "Economies of scale, adult equivalent scales and bargaining power", paper presented at ESEM'02, Venice.

[47] Lise, J. and S. Seitz (2004): "Consumption inequality and intra-household allocations", Queens University working paper.

[48] Lundberg S.J., R.A. Pollak and T.J. Wales (1997): " Do Husbands and Wives Pool Their Resources? Evidence from the U.K. Child Benefit", The Journal of Human Resources, 32, 3, 463-480.

[49] MaCurdy, T. (1992): "Work Disincentives Effects of Taxes: A Reexamination of some evidence", American Economic Review, Papers and Proceedings, 82, 243-249.

[50] Mirrlees, J.A. (1971) : "An exploration in the Theory of Optimum Income Taxation", Review of Economic Studies, 38.

[51] Mirrlees, J.A. (1986) : "The Theory of Optimum Income Taxation", Handbook of Mathematical Economics, Elsevier North-Holland.

[52] Moreau, N. and O. Donni (2002): "Une estimation d'un modèle collectif d'offre de travail avec taxation", Annales d'Economie et de Statistiques, 62, 55-83.

[53] Muellbauer, J. and J. Van de Ven (2004): "Estimating equivalence scales for tax and benefits system", mimeo.

[54] Peluso, E. and A. Trannoy (2003): "Inequality and welfare comparisons among individuals under Samuelson's model of households", mimeo. 
[55] Peluso, E. and A. Trannoy (2004): "Does less inequality among households mean less inequality among individuals?", mimeo.

[56] Spadaro (1999), Microsimulation des réformes fiscales : trois essais dans une perspective européenne, thèse de doctorat, EHESS.

[57] Spadaro, A. (2004): "Microsimulation and normative policy evaluation: an application to some EU Tax-Benefits system", Journal of Public Economic Theory, forthcoming.

[58] Stern, N. (1976): "On the Specification of Models of Optimum Income Taxation", Journal of Public Economics, 6, 123-162.

[59] Tuomala M. (1990), Optimal Income Tax and Redistribution, Oxford University Press

\section{Appendices}

\subsection{Calibration of Individual Productivities}

\subsubsection{Interior Solution of the Optimal Program}

In an interior solution and with the specifications introduced in the text, first-order conditions of the optimal program are written:

$$
\begin{aligned}
c_{f} & =\underline{c}_{f}+\frac{\mu \beta_{f}^{c}}{\lambda} \\
c_{m} & =\underline{c}_{m}+\frac{(1-\mu) \beta_{m}^{c}}{\lambda} \\
e_{f} & =T_{f}-\frac{\mu \beta_{f}^{l}+(1-\mu) \delta}{\lambda \widetilde{\omega}_{f}} \\
e_{m} & =T_{m}-\frac{(1-\mu) \beta_{m}^{l}+\mu \delta}{\lambda \widetilde{\omega}_{m}},
\end{aligned}
$$

with $\lambda$ the Lagrange multiplier. The first two equations give:

$$
\begin{aligned}
c & =c_{f}+c_{m}=\underline{c}+\frac{\mu \beta_{f}^{c}+(1-\mu) \beta_{m}^{c}}{\lambda} \\
\text { avec } \underline{c} & =\underline{c}_{f}+\underline{c}_{m},
\end{aligned}
$$

hence an expression:

$$
\lambda=\frac{\mu \beta_{f}^{c}+(1-\mu) \beta_{m}^{c}}{c-\underline{c}},
$$

which is plugged in first-order conditions to yield the following conditional functions:

$$
\begin{aligned}
c_{f} & =\underline{c}_{f}+\frac{\mu \beta_{f}^{c}}{\mu \beta_{f}^{c}+(1-\mu) \beta_{m}^{c}}(c-\underline{c}) \\
c_{m} & =\underline{c}_{m}+\frac{(1-\mu) \beta_{m}^{c}}{\mu \beta_{f}^{c}+(1-\mu) \beta_{m}^{c}}(c-\underline{c}) \\
e_{f} & =T_{f}-\frac{\mu \beta_{f}^{l}+(1-\mu) \delta}{\mu \beta_{f}^{c}+(1-\mu) \beta_{m}^{c}} \frac{c-\underline{c}}{\widetilde{\omega}_{f}} \\
e_{m} & =T_{m}-\frac{(1-\mu) \beta_{m}^{l}+\mu \delta}{\mu \beta_{f}^{c}+(1-\mu) \beta_{m}^{c}} \frac{c-\underline{c}}{\widetilde{\omega}_{m}} .
\end{aligned}
$$


To assure the existence and unicity of the optimal allocation, the budget constraint is convexified, as described in the text. We also assume that the linear function of individual utilities in expression (3) is strictly concave, i.e., that the Hessian of $W\left(c_{f}, c_{m}, l_{f}, l_{m}\right)$ is negative definite. It is simple to show that the Hessian is diagonal and that all the terms are negative.

Conditional effort supplies are written:

$$
\begin{aligned}
e_{f} & =T_{f}-B_{f} \frac{c-\underline{c}}{\widetilde{\omega}_{f}} \\
e_{m} & =T_{m}-B_{m} \frac{c-\underline{c}}{\widetilde{\omega}_{m}} \\
\text { with } B_{f} & =\frac{\mu \beta_{f}^{l}+(1-\mu) \delta}{\mu \beta_{f}^{c}+(1-\mu) \beta_{m}^{c}} \text { and } B_{m}=\frac{(1-\mu) \beta_{m}^{l}+\mu \delta}{\mu \beta_{f}^{c}+(1-\mu) \beta_{m}^{c}}
\end{aligned}
$$

so that:

$$
\begin{aligned}
e_{f} & =T_{f}-B_{f} \frac{\widetilde{\omega}_{f} e_{f}+\widetilde{\omega}_{m} e_{m}+\widetilde{y}_{0}-\underline{c}}{\widetilde{\omega}_{f}} \\
e_{m} & =T_{m}-B_{m} \frac{\widetilde{\omega}_{f} e_{f}+\widetilde{\omega}_{m} e_{m}+\widetilde{y}_{0}-\underline{c}}{\widetilde{\omega}_{m}} .
\end{aligned}
$$

This system leads to (unconditional) marshallian functions:

$$
\begin{aligned}
e_{f} & =\frac{1}{1+B_{m}+B_{f}}\left[\left(1+B_{m}\right) T_{f}-\frac{B_{f}}{\widetilde{\omega}_{f}}\left(\widetilde{y}_{0}-\underline{c}+\widetilde{\omega}_{m} T_{m}\right)\right] \\
e_{m} & =\frac{1}{1+B_{m}+B_{f}}\left[\left(1+B_{f}\right) T_{m}-\frac{B_{m}}{\widetilde{\omega}_{m}}\left(\widetilde{y}_{0}-\underline{c}+\widetilde{\omega}_{f} T_{f}\right)\right] .
\end{aligned}
$$

Naturally, this solution is only valid locally since implicit productivities $\widetilde{\omega}$ are endogenous to the effort supply.

\subsubsection{Inversion for Interior Solutions}

Total consumption $c$ is known (microsimulated from the observed gross incomes) so that it is easier to use conditional functions (9) and (10) rather than unconditional functions to recover individual productivities; these functions together with the expression of the power index give the following system of three unknowns $\left(\mu, \omega_{f}\right.$ and $\left.\omega_{m}\right)$ :

$$
\begin{aligned}
y_{f} & =T_{f} \omega_{f}-\frac{\mu \beta_{f}^{l}+(1-\mu) \delta}{\mu \beta_{f}^{c}+(1-\mu) \beta_{m}^{c}} \frac{c-\underline{c}}{1-t_{f}} \\
y_{m} & =T_{m} \omega_{m}-\frac{(1-\mu) \beta_{m}^{l}+\mu \delta}{\mu \beta_{f}^{c}+(1-\mu) \beta_{m}^{c}} \frac{c-\underline{c}}{1-t_{m}} \\
\mu & =\frac{\omega_{f}}{\omega_{f}+\omega_{m}} .
\end{aligned}
$$

Equations can be inverted to give:

$$
\begin{aligned}
\omega_{f} & =\left[y_{f}+\frac{\mu \beta_{f}^{l}+(1-\mu) \delta}{\mu \beta_{f}^{c}+(1-\mu) \beta_{m}^{c}} \frac{c-\underline{c}}{1-t_{f}}\right] / T_{f} \\
\omega_{m} & =\left[y_{m}+\frac{(1-\mu) \beta_{m}^{l}+\mu \delta}{\mu \beta_{f}^{c}+(1-\mu) \beta_{m}^{c}} \frac{c-\underline{c}}{1-t_{m}}\right] / T_{m} \\
\omega_{f} & =\omega_{m} \frac{\mu}{1-\mu} .
\end{aligned}
$$


To simplify expressions, note the 'before linearized tax' income:

$$
\begin{aligned}
s_{i} & =\frac{c-\underline{c}}{1-t_{i}} \\
& =\frac{g\left(y_{f}, y_{m}, Z\right)-\underline{c}}{\partial g\left(y_{f}, y_{m}, Z\right) / \partial y_{i}} \\
& =s_{i}\left(y_{f}, y_{m}\right),
\end{aligned}
$$

so that the system simply leads to the equation:

$$
\begin{aligned}
& (1-\mu) T_{m}\left[y_{f}+\frac{\mu\left(\beta_{f}^{l}-\delta\right)+\delta}{\mu\left(\beta_{f}^{c}-\beta_{m}^{c}\right)+\beta_{m}^{c}} s_{f}\right] \\
= & \mu T_{f}\left[y_{m}+\frac{\mu\left(\delta-\beta_{m}^{l}\right)+\beta_{m}^{l}}{\mu\left(\beta_{f}^{c}-\beta_{m}^{c}\right)+\beta_{m}^{c}} s_{m}\right],
\end{aligned}
$$

which is developed as follows:

$$
\begin{aligned}
& (1-\mu)\left[y_{f} T_{m}\left(\mu\left(\beta_{f}^{c}-\beta_{m}^{c}\right)+\beta_{m}^{c}\right)+\left(\mu\left(\beta_{f}^{l}-\delta\right)+\delta\right) s_{f} T_{m}\right] \\
= & \mu\left[y_{m} T_{f}\left(\mu\left(\beta_{f}^{c}-\beta_{m}^{c}\right)+\beta_{m}^{c}\right)+\left(\mu\left(\delta-\beta_{m}^{l}\right)+\beta_{m}^{l}\right) s_{m} T_{f}\right] .
\end{aligned}
$$

It is rearranged to give the quadratic expression in $\mu$ :

$$
\begin{aligned}
& \mu^{2}\left[\left(y_{m}^{*} T_{f}+y_{f}^{*} T_{m}\right)\left(\beta_{f}^{c}-\beta_{m}^{c}\right)+\left(\beta_{f}^{l}-\delta\right) s_{f}^{*} T_{m}+\left(\delta-\beta_{m}^{l}\right) s_{m}^{*} T_{f}\right] \\
& +\mu\left[\left(y_{m}^{*} T_{f}+y_{f}^{*} T_{m}\right) \beta_{m}^{c}-y_{f}^{*} T_{m}\left(\beta_{f}^{c}-\beta_{m}^{c}\right)-\left(\beta_{f}^{l}-2 \delta\right) s_{f}^{*} T_{m}+\beta_{m}^{l} s_{m}^{*} T_{f}\right] \\
& -\left[y_{f}^{*} T_{m} \beta_{m}^{c}+\delta s_{f}^{*} T_{m}\right]=0,
\end{aligned}
$$

expressed for observed values of gross incomes $y_{i}^{*}{ }_{(i=f, m)}$, total consumption $c^{*}$, and effective marginal tax rates $t_{i}^{*}(i=f, m)$ (or equivalently $s_{i(i=f, m)}^{*}$ ). This equation is solved numerically, one of the two roots being automatically rejected as it does not stand in $[0,1]$.

\subsubsection{Corner Solution of the Optimal Program}

The question of participation in a collective framework has been analyzed theoretically by Donni (2002). The author proves the existence of a reservation productivity, below which a spouse does not work, and demonstrates that the uniqueness does not stem from the theoretical background, as for the unitary model, and must be postulated. This is due to the fact that the reservation productivity depends on the other spouse's productivity. We can illustrate this in the present setting, defining $s_{i}\left(y_{f}, y_{m}\right)$ as above.

When both spouses are inactive, first-order conditions yield the system:

$$
\begin{aligned}
& 0 \geq T_{f}-B_{f} \frac{\widetilde{y}_{0}-\underline{c}}{\widetilde{\omega}_{f}} \\
& 0 \geq T_{m}-B_{m} \frac{\widetilde{y}_{0}-\underline{c}}{\widetilde{\omega}_{m}} .
\end{aligned}
$$

Naturally, implicit productivities are endogenous to productive efforts since we are in presence of nonlinear taxation. Let us ignore taxation for a moment and assume $\delta=0$ (egoistic preferences) to simplify the demonstration. After small transformations, the previous system becomes:

$$
\begin{aligned}
& \omega_{f} \leq \beta_{f}^{l} \frac{y_{0}-\underline{c}}{T_{f}}-\omega_{m} \frac{\beta_{m}^{c}}{\beta_{f}^{c}}=\bar{\omega}_{f}\left(\omega_{m}\right) \\
& \omega_{m} \leq \beta_{m}^{l} \frac{y_{0}-\underline{c}}{T_{m}}-\omega_{f} \frac{\beta_{f}^{c}}{\beta_{m}^{c}}=\bar{\omega}_{m}\left(\omega_{f}\right) .
\end{aligned}
$$


It then appears that reservation productivities as defined above for each spouse depend on the partner's productivity. Donni (2003) gives an interpretation in terms of sharing rule in a decentralized version of the collective model with egoistic preferences (the same framework as in Chiappori, 1988, 1992). Let us study, for instance, the case where the wife is inactive and the husband is on his participation frontier, that is, the case where only equation (12) is binding. A decrease of the wife's productivity (e.g., her human capital depreciates) implies a redistribution in favor of the husband (he receives a larger share of the non labor income in the sharing rule interpretation), that is, a positive income effect which discourages his effort supply. This corresponds to an increase of the reservation productivity of the husband through the second term of the right-hand side in (12). Functions $\bar{\omega}_{m}$ and $\bar{\omega}_{f}$ are monotonic decreasing and define the non-participation zones of the household as illustrated by Donni (2003).

In the case of one-earner couples (the husband works), first-order conditions become:

$$
\begin{aligned}
0 & \geq T_{f}-B_{f} \frac{\omega_{m} e_{m}+y_{0}-\underline{c}}{\omega_{f}} \\
e_{m} & =T_{m}-B_{m} \frac{\omega_{m} e_{m}+y_{0}-\underline{c}}{\omega_{m}} .
\end{aligned}
$$

The second expression gives the solution for the husband:

$$
e_{m}=\frac{T_{m}}{B_{m}+1}-\frac{B_{m}\left(y_{0}-\underline{c}\right)}{\left(B_{m}+1\right) \omega_{m}},
$$

and the first expression then becomes:

$$
0 \geq\left(B_{m}+1\right) \omega_{f} T_{f}-B_{f}\left(y_{0}-\underline{c}\right)-B_{f} \omega_{m} T_{m},
$$

which gives:

$$
\omega_{f} \leq \frac{\beta_{f}^{l}}{T_{f} \beta_{f}^{c}}\left(y_{0}-\underline{c}+\omega_{m} T_{m}\right)-\frac{\omega_{m}}{\beta_{f}^{c}}=\bar{\omega}_{f}\left(\omega_{m}\right)
$$

and define a reservation productivity for the wife. When the productivity of the husband increases (e.g., learning-by-doing), the distribution effect described previously implies a decrease of the implicit transfer to the wife (i.e., a shift of the sharing rule in favor of the husband) hence, a negative income effect or equivalently, a decrease in her reservation productivity in (13). Unlike in expression (11), a positive income effect comes also into play as the husband's productivity increases. The wife benefits from this effect which corresponds to an increase of her reservation productivity (first term of the right-hand side in (13)). We also have:

$$
\bar{\omega}_{f}^{\prime}\left(\omega_{m}\right)=\frac{1}{\beta_{f}^{c}}\left(\frac{T_{m} \beta_{f}^{l}}{T_{f}}-1\right) .
$$

Donni (2003) assumes that the direct income effect dominates the distribution effect, which would imply here that $\frac{T_{m} \beta_{f}^{l}}{T_{f}}>1$.

\subsubsection{Inversion for Corner Solutions}

We now come back to the initial set-up with taxation and non-egoistic preferences. Recall that cases where households are either inactive or in which only the women work are very few after the selection procedure and are taken out of the final selected sample. We then focus on corner solutions for one-earner 
couples where the husband works. As for interior solutions, we prefer to use expressions conditional to the total consumption level. First-order conditions lead to:

$$
\begin{aligned}
0 & \geq T_{f}-\frac{\mu \beta_{f}^{l}+(1-\mu) \delta}{\mu \beta_{f}^{c}+(1-\mu) \beta_{m}^{c}} \frac{s_{f}}{\omega_{f}} \\
e_{m} & =T_{m}-\frac{(1-\mu) \beta_{m}^{l}+\mu \delta}{\mu \beta_{f}^{c}+(1-\mu) \beta_{m}^{c}} \frac{s_{m}}{\omega_{m}},
\end{aligned}
$$

which gives, together with the expression of the power index:

$$
\begin{aligned}
\omega_{f} & \leq \frac{\mu \beta_{f}^{l}+(1-\mu) \delta}{\mu \beta_{f}^{c}+(1-\mu) \beta_{m}^{c}} \frac{s_{f}}{T_{f}} \\
\omega_{m} & =\left[y_{m}+\frac{(1-\mu) \beta_{m}^{l}+\mu \delta}{\mu \beta_{f}^{c}+(1-\mu) \beta_{m}^{c}} s_{m}\right] / T_{m} \\
\mu & =\frac{\omega_{f}}{\omega_{f}+\omega_{m}} .
\end{aligned}
$$

It is obvious that when the wife does not work, her productivity cannot be recovered. However, inequality (16) allows in theory to retrieve her reservation productivity, as suggested previously. It then becomes possible to follow Spadaro (2004) and to suggest alternative hypothesis on the distribution of productivities for inactive agents in order to draw values for each of them (reservation productivities being a natural upper bound to these draws). It is unfortunately the case that non-linear taxation prevents from deriving a simple analytical expression for the reservation productivity.

Instead, a numerical approach is easy to conduct and, instead of drawing a random value for the productivity, we assume that index $\mu$ follows a normal low with mean 0.5 and variance such that it is distributed in the $[0,1]$ interval. Then, we use (17) to compute $\omega_{m}$ and (18) to compute $\omega_{f}$. The procedure is repeated until condition (16) - which implicitly defines the reservation threshold of the wife - is verified.

Another condition must also be respected. Figure 1 shows that there may be a tangency on the convex budget set (grey curve) but also a corner solution (inactive couple). Consequently, it must be checked that the productivity draw for the inactive wife is compatible with the fact that it is optimal for the husband to work. When the wife is inactive, this condition is simply written:

$$
\mu U_{f}\left(c_{f}, 0, e_{m}\right)+(1-\mu) U_{m}\left(c_{m}, e_{m}, 0\right)>\mu U_{f}\left(c_{f}, 0,0\right)+(1-\mu) U_{m}\left(c_{m}, 0,0\right),
$$

and, using the functional forms, it is easy to show that it becomes:

$$
\left.\left[\mu \beta_{f}^{c}+(1-\mu) \beta_{m}^{c}\right] \ln \frac{g\left(0, y_{m}, Z\right)-\underline{c}}{g(0,0, Z)-\underline{c}}+\left[\mu \delta+(1-\mu) \beta_{m}^{l}\right] \ln \left(1-\frac{y_{m}}{\omega_{m} T_{m}}\right)\right]>0 .
$$

\subsection{Simulation of Behavioral Responses}

The simulation of an exogenous shock on the budget constraint (shock on productivities, tax reform, etc.) is conducted by using the calibrated productivities together with the behavioral model and the microsimulation program. The new budget constraint is symbolized by $g^{\text {new }}$. Equations (7) and (8) can be rewritten as:

$$
\begin{aligned}
c_{f}-\underline{c}_{f} & =p(c-\underline{c}) \\
c_{m}-\underline{c}_{m} & =(1-p)(c-\underline{c}),
\end{aligned}
$$


with

$$
p=\frac{\mu \beta_{f}^{c}}{\mu \beta_{f}^{c}+(1-\mu) \beta_{m}^{c}},
$$

the share of 'net' consumption obtained by the wife. This share is entirely determined by individual preference terms related to consumption and by the power index.

First, let us treat the case of two-earner couples. For a given pair of effort supplies $\left(e_{f}, e_{m}\right)$, we simply compute the new level of disposable income so that individual consumptions are obtained as:

$$
\begin{aligned}
c_{f} & =p\left[g^{\text {new }}\left(\omega_{f} e_{f}, \omega_{m} e_{m}, Z\right)-\underline{c}\right]+\underline{c}_{f} \\
c_{m} & =(1-p)\left[g^{\text {new }}\left(\omega_{f} e_{f}, \omega_{m} e_{m}, Z\right)-\underline{c}\right]+\underline{c}_{m} .
\end{aligned}
$$

The collective program then simplifies into the maximization of the household index $W\left(e_{f}, e_{m}\right)$ which only depends on the pair of effort supplies. The crucial point here is that the maximization is conducted by discretizing effort supplies (with a step small enough to simulate continuity) and looping numerically over the set of possible values for $\left(e_{f}, e_{m}\right)$ so as to find the pair of values which maximizes $W\left(e_{f}, e_{m}\right)$. Note $\left(c_{f}^{1}, c_{m}^{1}, e_{f}^{1}, e_{m}^{1}\right)$ the optimal allocation and $W^{1}$ the corresponding value of the household index.

In the case where the wife is not working, individual consumptions are written:

$$
\begin{aligned}
c_{f} & =p\left[g^{\text {new }}\left(0, \omega_{m} e_{m}, Z\right)-\underline{c}\right]+\underline{c}_{f} \\
c_{m} & =(1-p)\left[g^{\text {new }}\left(0, \omega_{m} e_{m}, Z\right)-\underline{c}\right]+\underline{c}_{m},
\end{aligned}
$$

so that the collective program simplifies into the maximization of the household index $W\left(0, e_{m}\right)$ which only depends on the husband's effort. Denote $\left(c_{f}^{2}, c_{m}^{2}, 0, e_{m}^{2}\right)$ the optimal allocation and $W^{2}$ the corresponding value of the household index. The symmetrical case where only the wife is working gives the optimal allocation $\left(c_{f}^{3}, c_{m}^{3}, e_{f}^{3}, 0\right)$ and a corresponding index value $W^{3}$. Finally, an inactive couple would correspond to the allocation $\left(c_{f}^{4}, c_{m}^{4}, 0,0\right)$ with an index value $W^{4}$.

The algorithm defines the optimal allocation $i$ chosen by the household such that:

$$
W\left(c_{f}^{i}, c_{m}^{i}, e_{f}^{i}, e_{m}^{i}\right)=\max \left(W^{1}, W^{2}, W^{3}, W^{4}\right) .
$$

The discrete approach to maximization dispenses from local linearization of the budget constraint (as in the inversion step for two-earner couples). A consequence of this is that any type of budget set - including non-convex sets - can be handled in the situation when a shock occurred (e.g., tax reform). 